\title{
Phycobilins and Phycobiliproteins Used in Food Industry and Medicine
}

\author{
Beata Mysliwa-Kurdziel $^{1 \#}$ and Katalin Solymosi ${ }^{2 \#} *$ \\ ${ }^{1}$ Department of Plant Physiology and Biochemistry, Faculty of Biochemistry, Biophysics and Biotechnology, Jagiellonian \\ University, Krakow, Poland; ${ }^{2}$ Department of Plant Anatomy, Eötvös Loránd University, Budapest, Hungary
}

\begin{abstract}
Open tetrapyrroles termed phycobilins represent the major photosynthetic accessory pigments of several cyanobacteria and some eukaryotic algae such as the Glaucophyta, Cryptophyta and Rhodophyta. These pigments are covalently bound to so-called phycobiliproteins which are in general organized into phycobilisomes on the thylakoid membranes. In this work we first briefly describe the physico-chemical properties, biosynthesis, occurrence, in vivo localization and roles of the phycobilin pigments and the phycobiliproteins. Then the potential applications and uses of these pigments, pigment-protein complexes and related products by the food industry (e.g., as LinaBlue ${ }^{\circledR}$ or the so-called spirulina extract used as coloring food), by the health industry or as fluorescent dyes are critically reviewed. In addition to the stability, bioavailability and safety issues of purified phycobilins and phycobiliproteins, literature data about their antioxidant, anticancer, anti-inflammatory, immunomodulatory, hepatoprotective, nephroprotective and neuroprotective effects, and their potential use in photodynamic therapy (PDT) are also discussed.
\end{abstract}

Keywords: Antioxidant, cancer, chemoprevention, food colorant, phycobilins, phycobiliproteins, phycocyanin, spirulina.

\section{INTRODUCTION}

Phycobilin is a term meaning 'algal bile' ( bilis, phycos bilis) and designates special open chain tetrapyrroles present as photosynthetic accessory pigments in several cyanobacteria and eukaryotic algal groups (i.e., Glaucophyta, Cryptophyta and Rhodophyta). Brilliantly blue extracts from Oscillatoria sp. containing phycobilins and showing red fluorescence were first described in the 19th century [1,2]. Such extracts were used for the first spectroscopic analyses and contributed to the development of fluorescence spectroscopy $[3,4]$ and are still nowadays widely used as fluorescent dyes.

Phycobilins and phycobiliproteins of photosynthetic organisms are used as natural colorants, coloring food, in dietary supplements and/or to prepare fortified and functional products [5,6]. Along with chlorophyllous pigments (reviewed in $[5,7,8]$ ), they are almost the only natural alternatives to greenish or bluish food colorants. In addition, phycobilin-containing products are also used in the health industry.

In the present paper we first review the chemical and physical properties of phycobilins, their biosynthetic pathways, roles and occurrence in vivo. We also discuss the

*Address correspondence to this author Department of Plant Anatomy, Eötvös Loránd University, Pázmány P. s. 1/C, H-1117 Budapest, Hungary; Tel: +361-381-2165; Fax: +361-381-2166; E-mails: katalin.solymosi@ttk.elte.hu, solymosikata@hotmail.com

"These authors contributed equally to the work. applications of phycobilins and phycobiliproteins in the food industry along with their health benefits as well as problems related to their use, i.e., data about their stability, safety and toxicology. The global market value of phycobiliprotein products has been estimated to reach 60 million USD in 2013 [9]. The size of this market is, however, expected to expand due to increasing consumer's demand in natural blue and green food colorants and the nomenclatural and compositional problems surrounding the use of water-soluble chlorophyll (Chl) derivatives in the food industry.

\section{CHEMICAL AND PHYSICAL PROPERTIES OF PHYCOBILINS}

Phycobilins are open-chain (i.e., linear) tetrapyrroles and, in their chemical structure, similar to bilins in animal cells (reviewed in [10-12]). Phycobilins absorb light from the visible radiation range which is poorly absorbed by Chl [12], and thus allow organisms to live in deep-water niches.

In Cyanobacteria, Glaucophyta and Rhodophyta, phycocyanins and phycoerythrins are the major phycobiliproteins containing the blue-colored phycocyanobilin and the red-colored phycoerythrobilin (Fig. 1). The different color of the pigments is due to their different structures, i.e., phycoerythrobilin contains six conjugated double bonds and absorbs at lower wavelengths than phycocyanobilin that has eight conjugated double bonds [13]. 


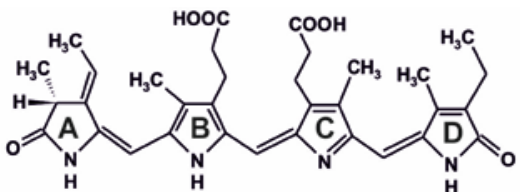

phycocyanobilin

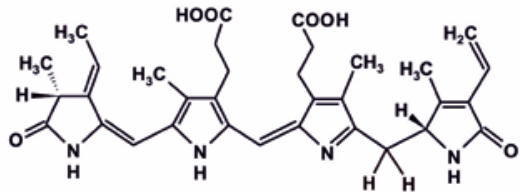

phycoerythrobilin

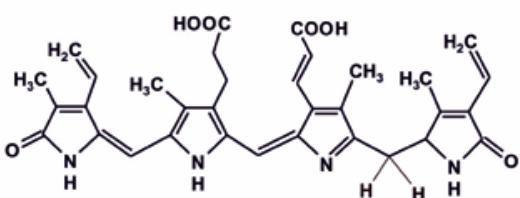

bilin-618

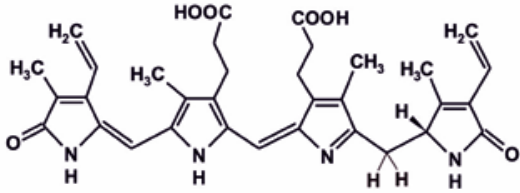

15, 16-dihydrobiliverdin

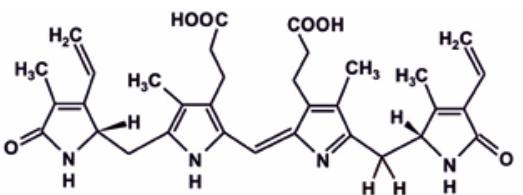

phycourobilin

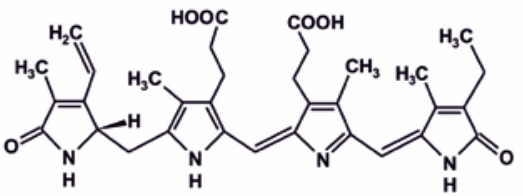

phycoviolobilin

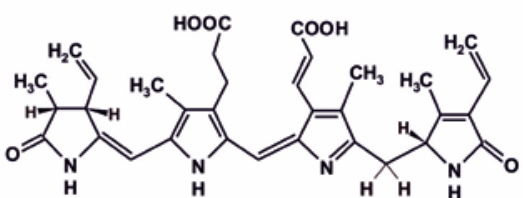

bilin-584

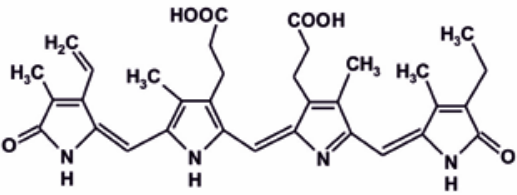

$18^{1}, 18^{2}$-dihydrobiliverdin

Fig. (1). Chemical structures of the major phycobilins.

In addition, two more phycobilins, namely yellowcolored phycourobilin, and purple-colored phycoviolobilin (also named cryptoviolin) were identified (reviewed in $[14,15])$. Phycobiliproteins of Cyanobacteria, Glaucophyta and Rhodophyta contain certain combinations of these four phycobilins and are organized into large supramolecular structure called phycobilisome (reviewed in [11,14-17]; further discussed in Section 4). In Cryptophyta, which do not have phycobilisomes, other bilins were found besides phycocyanobilin and phycoerythrobilin. The analysis of the Cryptophyta strain CBD led to the determination of the chemical structure of bilin 618 and bilin 584 (Fig. 1) both having acrylic acid side chain and differing in the number of conjugated double bonds [18]. In another strain, 15,16dihydrobiliverdin and $18^{1}, 18^{2}$-dihydrobiliverdin (mesobiliverdin) were identified [19]. The presence of various types of phycobilins differing in absorption characteristics contributes to the adaptation of Cryptophyta cells to individual environmental light conditions.
Absorption properties of phycobilins are determined by their chemical structure, mainly by the number and the arrangement of conjugated double bonds (Fig. 1). In photosynthetic organisms, phycobilins are covalently linked to specific proteins and form together phycobiliproteins (further discussed in Section 4). The absorption properties of phycobiliproteins and hence the variety of colors observed in phycobilin-containing organisms depend on (i) the properties of chromophores, (ii) the linkage of phycobilins to proteins and (iii) the molecular organization of the phycobiliproteins, in particular, their aggregation state (thoroughly discussed in [11,14,15,20]).

Concerning the chemical structure of phycobilins, four pyrrole rings are bound via single carbon bridges (Fig. 1). Terminal rings (A and D) have oxygen atoms (as ketone groups) and sites forming bonds with proteins. The internal rings have propionate or acryloyl residues. Unlike Chls these compounds do not contain metal ions. Phycobilins are covalently bound to the biliprotein via one or two thioether 
bonds $[11,14]$. In solution, when detached from the protein, bilins exist as mixtures of configurational, conformational, and tautomeric forms [11]. Photophysical properties of phycobilins have been summarized by [11]. In general, phycobilins absorb visible light within the 450-700 nm range and, to lower extent, the UV radiation between 300-400 nm. In solution, they show weak fluorescence because of conformational flexibility enabling efficient radiationless molecule relaxation. However, they become highly fluorescent when bound to phycobiliproteins [21], probably due to enhanced rigidity of the bilin molecule maintained in an extended conformation through interactions with the protein [22,23]. Application of biliproteins as fluorescent

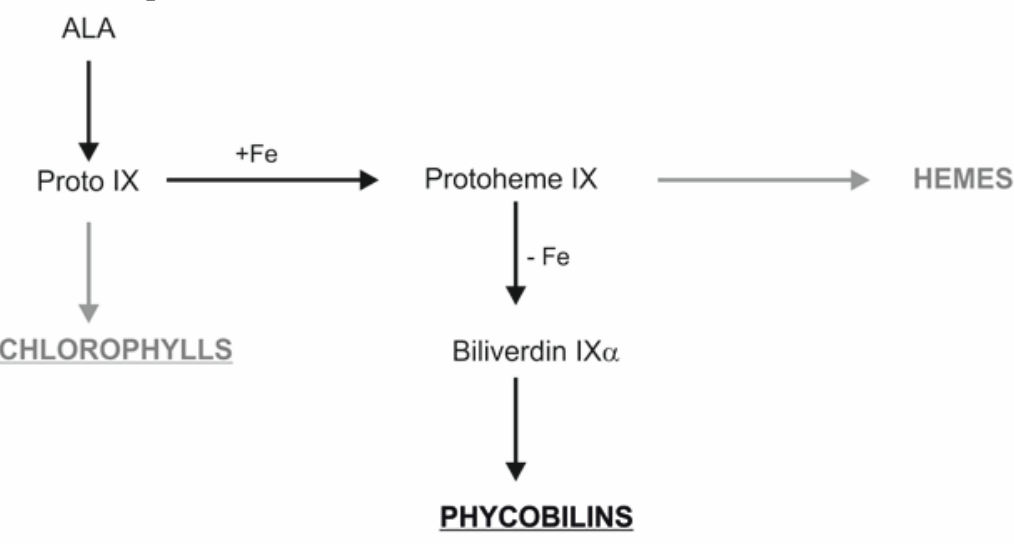$$
\text { ALA }
$$

labels for studying protein dynamics [20] is discussed in Section 6.4.

\section{BIOSYNTHESIS OF PHYCOBILINS}

Tetrapyrrole biosynthesis is a multi-branched, conserved and precisely regulated metabolic pathway (reviewed in [24-29]) (Fig. 2). Metabolic intermediates as well as the enzymes catalyzing particular reactions of tetrapyrrole biosynthesis have been mostly recognized (reviewed in [25,29-36]).

Fig. (2). Overview of phycobilin biosynthesis and its relation to chlorophyll and heme biosynthesis. Abbreviations: ALA, 5aminolevulinic acid; PROTO IX, protoporphyrin IX.

The biosynthesis of phycobilins proceeds via the heme biosynthetic pathway and coincides with Chl biosynthesis until the stage of protoporphyrin IX (PROTO IX) formation (reviewed in [7,10,15,37]). The chelation of PROTO IX backbone with $\mathrm{Fe}^{2+}$ ion leading to protoheme synthesis is the initial reaction of the Fe-branch of tetrapyrrole synthesis (Fig. 2), and protoheme is the direct substrate for phycobilin synthesis $[38,39]$. The synthesis of phycobilins starts with the opening of the protoheme macrocycle releasing $\mathrm{Fe}^{2+}$ and carbon monoxide [40,41]. This reaction is catalyzed by heme oxygenase ([42], reviewed in $[43,44])$. Algal heme oxygenase was first characterized for Cyanidium caldarium as soluble and ferredoxin-dependent plastid enzyme [45-47], which was confirmed for Synechocystis [48] and plants [49]. The reaction consumes three $\mathrm{O}_{2}$ molecules $[37,50]$.

Biliverdin IX $\alpha$, which is the product of the reaction catalyzed by heme oxygenase, is then reduced to form phycobilin molecules. Reduction of one or more double bonds of the outer rings of biliverdin IX $\alpha$ is catalyzed by enzymes belonging to ferredoxin-dependent bilin reductases (FDBR) [46]. To date, six classes of FDBR have been described (reviewed in [50,51]). Among reductases involved in phycobilin synthesis, phycocyanobilin:ferredoxin oxidoreductase (PcyA) is present in all cyanobacteria and is biochemically well characterized. It catalyzes the transfer of four electrons from ferredoxin to two distinct double bonds of biliverdin IX $\alpha$, leading to the formation of phycocyanobilin via $18^{1}, 18^{2}$-dihydrobiliverdin (mesobiliverdin) as intermediate [50,52]. Similarly, phycoerythrobilin synthase (PebS, present in marine cyanophages) catalyzes the two-step transfer of four electrons from ferredoxin to two distinct double bonds of biliverdin IX $\alpha$ to form phycoerythrobilin via 15,16dihydrobiliverdin. In cyanobacteria, 15,16dihydrobiliverdin:ferredoxin oxidoreductase (PebA) transfers two electrons to biliverdin IX $\alpha$ to form 15,16dihydrobiliverdin, which can be then converted to phycoerythrobilin due to another two-electron reduction catalyzed by phycoerythrobilin:ferredoxin oxidoreductase (PebB) [50,52]. However, the exact distribution of different classes of phycobilin reductases among various groups of photosynthetic organisms is beyond the topic of this article and is discussed elsewhere [50,51]. The last step in phycobiliprotein biosynthesis is the binding of phycobilins to specific apoproteins, which is either spontaneous or catalyzed by specific lyases (reviewed in [20,50]). Three classes of lyases have been recognized till now. One class of lyases (i.e., E/F-type lyases) also plays an additional role in the modification of phycobilin pigments during the attachment reaction, leading to the formation of phycoviolobilin and phycourobilin [20].

\section{OCCURRENCE, LOCALIZATION AND ROLES OF PHYCOBILINS IN VIVO}

Phycobilins are involved in capture of light for photosynthesis as accessory pigments absorbing and transferring sunlight energy from the antennae towards the reaction centres. Phycocyanobilin (also termed phycobiliverdin), phycoerythrobilin and less typically phycourobilin [53,54] and phycoviolobilin [51,55] 
commonly termed phycobilins are the only tetrapyrrole accessory pigments of (most) cyanobacteria (except prochlorophytes which have $\mathrm{Chl} b$ as accessory pigment and no phycobilins), glaucophytes and red algae. Cryptophyta contain both phycobilins and Chl $c$ as accessory pigments, however, their phycobilins are differently organized and localized than those of the other organisms mentioned above.

Similarly to Chls, phycobilin pigments are also bound to proteins located to the thylakoid membranes present either in the cytoplasm (in prokaryotic cyanobacteria) or in the chloroplasts (in case of eukaryotes) [56].

Open tetrapyrroles have important roles in the metabolism of photoautotrophic organisms. In plants, such molecules are present in low amounts as pigments bound to proteins (e.g., in phytochrome photoreceptors) and play crucial roles in plant morphogenesis and development [57]. However, in cyanobacteria, red algae, glaucophytes and in cryptophytes, open chain tetrapyrroles (phycobilins) involved in photosynthesis are abundant enough to mask the Chl molecules and carotenoids and confer their color to the whole organism [58]. Blue colored phycocyanobilin and red colored phycoerythrobilin are commonly found phycobilins present in large amounts, while orange-yellow phycourobilin [54] and purple phycoviolobilin (also termed cryptoviolin and phycobiliviolin) [51,55] are rarely occurring pigments, the latter serving as the photoreceptor pigment in cyanobacteriochrome involved for instance in the regulation of cyanobacterial phototaxis [51,55].

In situ, the ring A (or sometimes also ring D) of phycobilins (Fig. 1) are covalently bound to specific cystein groups of different hydrophilic proteins (called phycobiliproteins and also chromoproteins) via thioether linkage [59]. In cyanobacteria and red algae, phycobiliproteins are formed by two subunits forming a basic $\alpha \beta$ heterodimer, that has been shown to aggregate into $(\alpha \beta)_{3}$ trimers (e.g., in allophycocyanin) or $(\alpha \beta)_{6}$ hexamers (phycocyanin and phycoerythrin) acquiring ring structures $[53,54,60]$. Phycobiliproteins bind different numbers of the distinct phycobilin molecules: allophycocyanins and phycocyanins bind phycocyanobilin, while phycoerythrins bind phycoerythrobilin or sometimes also phycourobilin. Due to their distinct molecular environment, the phycobilin pigments of the three phycobiliproteins absorb different wavelengths of visible light and have thus different colors. Allophycocyanin is bluish green (bright aqua blue color), phycocyanin is dark cobalt blue, and phycoerythrin is purple (bright pink), with absorption and fluorescence emission maxima at $650-655 \mathrm{~nm} / \sim 660 \mathrm{~nm}, 610-620 \mathrm{~nm} / \sim 637 \mathrm{~nm}$ and $540-570 \mathrm{~nm} / \sim 577 \mathrm{~nm}$, respectively [59,61]. In addition, the major classes of phycocyanins and phycoerythrins also contain different phycobiliprotein-pigment complexes. They may be artificially classified as C- and R-phycocyanin, present in cyanobacteria and red algae, respectively, Rphycocyanin obtained from Synechococcus, C-phycoerythrin present in cyanobacteria, B- and R-phycoerythrins in red algae. These have slightly different absorption characteristics due to slight differences in their structure [60,62-64], however, detailed discussion of these forms is beyond the scope of this review. Orange-colored phycoerythrocyanin pigment-protein complexes binding phycoviolobilin and phycocyanobilin pigments and present in light-harvesting antennae of some cyanobacteria can be also distinguished with absorption and fluorescence emission maxima at $~ 575$ $\mathrm{nm} / \sim 607 \mathrm{~nm}[61,65]$ but are far less studied, and will be, therefore, not discussed in detail.

Cryptophyta have unique phycobiliprotein dimers in the thylakoid lumen $[66,67]$, while the phycobiliproteins of cyanobacteria, red algae and glaucophytes form large supramolecular aggregates - the so-called phycobilisomes (Fig. 3) - on the outer surface of the thylakoid membranes (or in few cyanobacteria also on the inner surface of the plasmamembrane). These phycobilisomes consist of a central core composed of allophycocyanin (located in the close vicinity of Chl $a$ during photosynthesis) and peripheral rods composed of phycocyanin and phycoerythrin hexamers (the latter are absent in some species, but are normally located at the periphery of the phycobilisomes) stacked on the top of each other $[13,53,68]$ and held together by several linker polypeptides that optimize light absorption and energy transfer within the phycobilisomes $[20,69,70]$. The pigments of phycobiliproteins have overlapping absorption and emission spectra that allow a non-radiative, direct and efficient transfer of the excitation energy among them along an energy gradient from the rods towards the photosystem II (PSII) core and partially to photosystem I (PSI) core [53,54]. In addition, to the phycobiliproteins discussed above, phycobilisomes are also structurally and spectroscopically well characterized light-harvesting antenna complexes, which absorb visible light in the $550-650 \mathrm{~nm}$ spectral region [59]. It may be noted, that several algal species (e.g., Galdieria red algae) are able to grow under heterotrophic and mixotrophic conditions, and when depleted in nitrogen, they dismantle their phycobilisomes and proteins using them as nitrogen source [71,72].

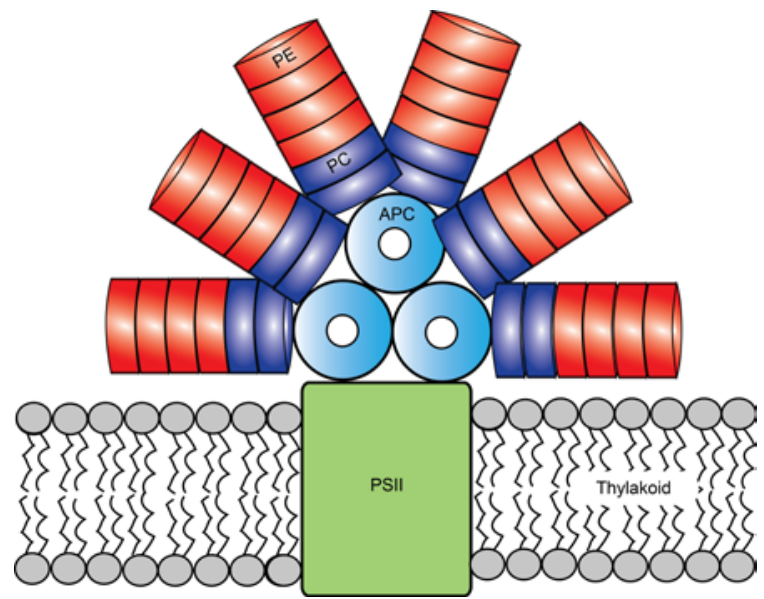

Fig. (3). Schematic representation of a hemidiscoidal phycobilisome located on the thylakoid membrane, in close connection with photosystem II (PSII). The phycobilisome consists of a three cylindrical allophycocyanin (APC) core and six lateral cylinders formed by phycocyanin (PC) and phycoerythrin (PE) hexamers.

Obviously, the light phase of photosynthesis and the photosynthetic pigments are located to thylakoids (or in some cyanobacteria to the plasma membrane), and the dark phase proceeds in either the cytoplasm (in case of prokaryotic photosynthetic organisms) or in the stroma of 
plastids (in eukaryotes) [59]. Phycobilisomes present at the membrane surface (Figs. 3 and 4) prevent the assembly and stacking of thylakoid membranes. Therefore, Cyanobacteria, Glaucophyta and Rhodophyta (Fig. 4) have single, unstacked thylakoids [53,56]. However, due to the absence of phycobilisomes, the thylakoids of Cryptophyta are parallelly arranged into bilayered lamellar assemblies without connection between the adjacent bands of two thylakoids $[53,56]$.

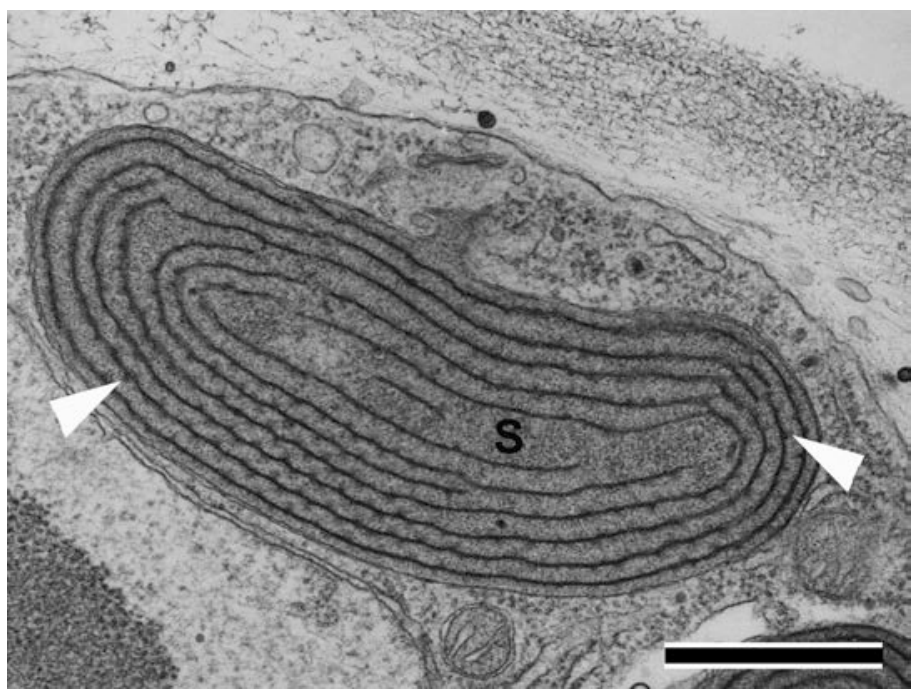

Fig. (4). Chloroplast containing single thylakoids with lightly stained phycobilisomes in the freshwater rhodophyte, Compsopogon caeruleus. Micrograph courtesy of Joe Scott, College of William and Mary, Virginia, United States. S: stroma; white arrowhead: phycobilisome on the thylakoid surface. Bar: $1 \mu \mathrm{m}$.

\section{SOURCES FOR INDUSTRIAL EXTRACTION}

Not phycobilin pigments alone, but their watersoluble protein-bound forms (phycoerythrin, allophycocyanin and phycocyanin) are in general used by the industry for different applications (see Section 6, reviewed by $[13,61,64])$. These may be obtained - along with Chls and carotenoids - from cell cultures of different cyanobacteria and red algae (e.g., phycoerythrin and phycocyanin from the cyanobacteria Arthrospira platensis and Arthrospira maxima, phycoerythrin from the red alga Porphyridium cruentum, and phycocyanin from the red algae Porphyridium aerugineum and Galdieria sulphuraria or the cyanobacteria Oscillatoria quadripunctulata or Anabaena [13]) grown in bioreactors or different cultivation systems [13,64] (Fig. 5). For an updated review about microalgal sources for phycobiliprotein extraction see [73]. Up to $40 \%$ of the proteins of Arthrospira cells is phycocyanin [74]. However, extraction from cyanobacteria is not simple due to their special multilayered cell wall and the presence of contaminants, therefore, extraction usually results either in high purity or high efficiency. Isolation consists typically of two phases: (1) liberation of intracellular content by pretreatment to yield a crude extract (i.e., by precipitation, centrifugation, or other treatments including microwave- or ultrasound-assisted extraction [75,76]), isolation/purification step(s) that separate the pigment- protein complexes by conventional methods $[5,13,61,73,77-$ 81].

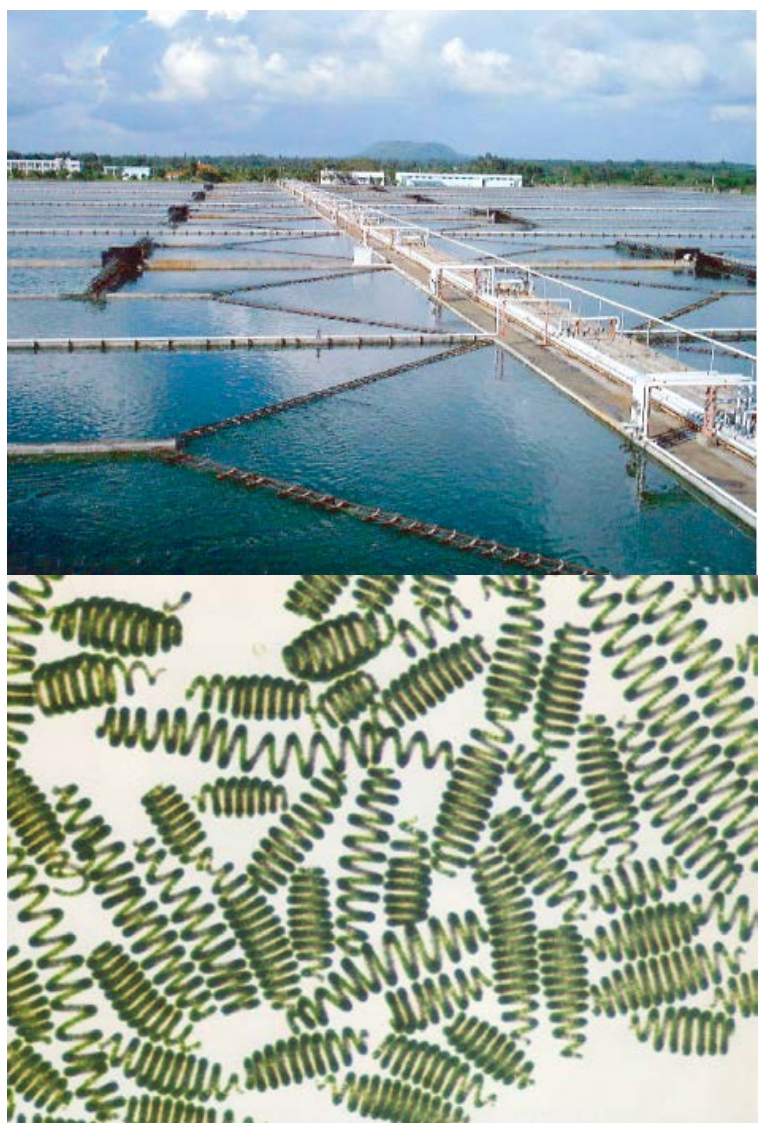

Fig. (5). Open ponds used for microalga cultivation (upper panel) and microscopic image showing spirulina (lower panel) (photo courtesy to DIC Corporation).

Phycocyanin is mostly extracted from Arthrospira [79,81-83] (Fig. 5, lower panel). After extraction a combination of gel adsorption and ion exchange chromatography can be used for purification. However, simpler (one-step), faster and more cost-efficient purification protocols are under development for this species (e.g., $[13,81])$, and extraction and purification from other species were also reported (e.g., [77,84], reviewed in [64]). Pure phycoerythrin can be obtained from the unicellular red microalga, Porphyridium cruentum [77], but protocols for other red micro- or macroalgal species have been also reported [85-88]. The use of anionic chromatographic column of DEAE cellulose seems to represent cost-effective large preparative technique for purification [77]. However, it has to be noted, that the calculated unit production costs of phycobiliprotein extraction and production (approx. 30,00060,000 USD per kg in 2004 [77]) results in very high market price (for pure phycobiliproteins, e.g., 5000-33,000 USD per $\mathrm{g}$ in case of Cyanotech products mostly in the form of fluorescent dyes in 2008 [61], and similarly high market price is typical also nowadays for these compounds). This is still quite expensive for food industry applications where relatively large quantities: e.g., $50-100 \mathrm{mg} \mathrm{kg}^{-1}$ and $140-180$ $\mathrm{mg} \mathrm{kg} \mathrm{k}^{-1}$ phycoerythrin and phycocyanin, respectively, are required to color food or beverages [89]. Therefore, further developments such as e.g., expanded bed adsorption 
chromatography [90-92], or methods allowing simultaneous recovery of different phycobiliproteins [79] are needed. Similarly, the efficiency of different extraction and isolation/purification steps using dry or wet biomass must be also carefully compared and optimized [13,64,93]. In addition, special care has to be taken during extraction and isolation (and also during subsequent use) to preserve the stability of the phycobiliprotein complexes [94], therefore, the temperature and $\mathrm{pH}$ values of extraction have to be carefully chosen [95] (see Section 6.1).

It is noteworthy to mention, that the food industry actually uses a so-called semi-purified spirulina extract to color food instead of highly expensive purified phycobiliproteins (see Section 6.2). The term spirulina is also used to designate the protein-rich dried algal (in fact cyanobacterial) biomass used as nutritious food and/or dietary supplement for humans. This persisting term ('spirulina') is based on a confusion, because although the edible cyanobacterial species used for its production are Arthrospira maxima and A. platensis, earlier they were often misidentified as Spirulina maxima and S. platensis that are in fact not used for the production of the so-called spirulina food colorant [96]. During large-scale production of spirulina, considerable amounts of inferior quality spirulina are obtained due to the presence of biotic and abiotic stressors (contamination with microorganisms or heavy metals) [91]. Low-quality spirulina is not suitable for direct human consumption but may be used as source for the isolation and purification of phycobiliprotein food colorants or other dyes [91].

\section{PHYCOBILINS AND PHYCOBILIPROTEINS AS HIGH VALUE COMPOUNDS}

Phycobilins may be used by the food industry and in medicine. Several companies deal with phycobilins (more exactly with phycobiliproteins): there is a great number of patents related to their production, to their applications in medicine, food and other areas (e.g., cosmetic industry), but most patents are related to their use as fluorescence dyes in clinical and immunological analyses [13,61]. However, there are several parameters - for instance the stability of the pigments - that have to be carefully considered before the potential industrial applications, and which will be thus first reviewed in Section 6.1.

\subsection{Stability}

Purified phycobiliproteins (i.e., pigment-protein complexes containing various proteins and phycobilins) are considered for industrial applications. There are contradictory data about the stability of phycobiliproteins, however, their stability varies among the distinct proteins and is also strongly influenced by $\mathrm{pH}[79,97]$, temperature [97,98], protein concentration, osmotic and ionic strengths [98], and the used purification methods, which may or may not dissociate the hexamers and/or other aggregates [63,99].

Several studies have shown that purified phycocyanin [74] and other phycobiliproteins, e.g., allophycocyanin $[79,100]$ remain stable (or at least do not get completely denaturated) over a large $\mathrm{pH}$ range (e.g., between $\mathrm{pH}$ 4-9
[79] or 7-10 [74,100]). Phycoerythrin has stable and long shelf life at $\mathrm{pH}$ 5-6 [89], especially when stored dry. Similarly, phycocyanin-colored dry food retained its color for more than 4 years [89]. Another advantage of phycobiliproteins - for instance when compared with anthocyanins - is that their color does not change with $\mathrm{pH}$.

Phycocyanin is insoluble in acidic solution below $\mathrm{pH}$ 3 , and is in general sensitive to light and heat stress (i.e., protein denaturation occurs above $45{ }^{\circ} \mathrm{C}$ resulting in color change) [101]. However, degradation processes depend on the $\mathrm{pH}$ and the structure of the phycobiliprotein (e.g., cyanobacterial phycocyanin may be less stable than Cphycocyanin from Porphyridium) [89]. Denaturation and bleaching of the phycobiliproteins and various phycobilin pigments have been shown to occur after several minutes of heat treatment at $60-65{ }^{\circ} \mathrm{C}$ in vivo in cyanobacterial and red algal cells, while virtually no alteration occurred in Chl or carotenoid absorption [98]. Similar phenomenon can be observed when the typical black color of dried laver (nori, Porphyra sp.) turns green when toasted and this color remains during storage for few days in vinegar [5,102]. However, sometimes undesirable reddish-brown coloration appears due to monomerization of phycoerythrin at low $\mathrm{pH}$ in vinegar and/or in vivo in cultivated nori when the fronds on frozen nursery-nets become damaged [103]. Interestingly, phycocyanin and phycoerythrin isolated from Porphyridium remain stable for 40 or 30 minutes, respectively, to heat stress (up to $65^{\circ} \mathrm{C}$ ) at lower $\mathrm{pH}$ values ( $\mathrm{pH} 4-5-6$ ) in vitro [89], and sorbitol can to some extent prevent the temperature-induced degradation of the protein, and thus the decoloration of phycocyanin [104].

Strong conditions (i.e., $1 \mathrm{M}$ sodium perchlorate and sodium thiocyanate) are in general needed to produce monomeric biliproteins, but even these conditions are not necessarily dissociating the monomers into their subunits [105]. On the other hand, temperature-induced bleaching of the pigments (occurring at $60-65{ }^{\circ} \mathrm{C}$ within few minutes) could be prevented in isolated phycobilisomes in the presence of high phosphate concentrations [98], indicating the complexity of the interactions determining phycobiliprotein stability. Evidently, in the presence of SDS $(1 \mathrm{mM})$ and other detergents (1.6-6.4 M urea) phycocyanin and allophycocyanin get denaturated.

In spite of the above-mentioned instabilities of phycocyanin, it seemed to be the most versatile blue food colorant in exploratory studies comparing indigo, gardenia blue and phycocyanin in soft drink, jelly gum, hard candy and coated soft candies [101].

\subsection{Use as Food Color Additives (Linablue ${ }^{\circledR}$ and Spirulina Extract)}

Open chain tetrapyrroles are potentially interesting for future food and nonfood industries as natural coloring agents in their water-soluble protein-bound forms [106]. In addition to enhanced solubility, these are also highly stable in the $\mathrm{pH}$ range of 4 to 9 [79]. Phycoerythrin has red color and may be considered as alternative red natural food coloring even in $\mathrm{pH}$ ranges where for instance anthocyanins are no longer red. In addition, phycoerythrin has yellow fluorescence that may be exploited in some new food 
products (candies, cake decorations, lollypops fluorescing under UV, alcoholic beverages fluorescing at $\mathrm{pH}$ 5-6) $[61,80]$, and it can be also incorporated to microemulsions of aerosols [63]. However, its shelflife for instance in alcoholic beverages is short [89].

More importantly, allophycocyanin and phycocyanin have bluish green and dark cobalt blue colors, respectively, hues which cannot be reproduced by almost any other natural coloring agent (with the exception of Chls and their derivatives, gardenia blue, indigo and marennine) $[6,7,80,101]$. However, comprehensive knowledge and technological base for augmenting the commercial utilities of phycobiliproteins is still lacking and several of their novel applications are reported only in patents (reviewed in [61]).

Phycobiliprotein colorants (especially phycocyanin) are considered non-toxic and non-carcinogenic and are used as blue colorants in some countries (e.g., in Japan, Australia [96], Thailand and China [81]) to color cosmetics (like lipstick and eye liners) [107] and food such as fermented milk products, ice creams and sorbets, popsicles, milk shakes and desserts, other dairy products, sweet cake decorations, chewing gum, candies, wasabi, different soft and alcoholic beverages [61]. Phycocyanin (isolated from Arthrospira) was first marketed under the brand name Linablue ${ }^{\circledR}$ by Dainippon Ink \& Chemicals Inc. (Japan, current name: DIC Corporation) in 1977-1980 [108] (Fig. 6).

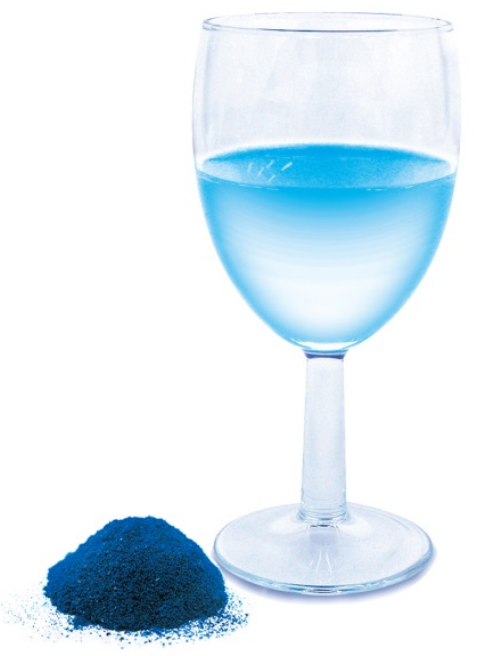

Fig. (6). LinaBlue ${ }^{\circledR}$ powder and solution in water (photo courtesy to DIC Corporation).

Due to the increasing need to replace artificial blue food colors, the phycobilins present in the so-called 'spirulina extract' (or simply spirulina) obtained by filtered aqueous extraction from the dried biomass of Arthrospira platensis cells have been recently accepted for safe use in candy (e.g., blue M\&M's) and chewing gum as a color additive in the United States since 2013 on demand of Mars, Inc. [109,110]. In 2014, the use of spirulina extracts at levels consistent with good manufacturing practice (GMP) has been extended to several products (fermented milk products, yogurts, milk shakes and desserts, puddings, other dairy products, ice creams, sorbets, popsicles, frostings and other frozen desserts, sweet cake decorations, dessert coatings and toppings, custards, gelatin, breadcrumbs, ready-to-eat cereals, cottage cheese, different soft and alcoholic beverages) [111] and to coating formulations applied to dietary supplements and drug tablets and capsules in 2015 [112]. Evidently, these contain all kinds of water-soluble components present in Arthrospira cells (e.g., other proteins, polysaccharides, vitamins, minerals, etc.) [109], therefore, special care has to be taken to avoid any contamination with cyanobacterial toxins and/or heavy metals. The originally regulated spirulina extract - as specified by the Federal Register - contained not less than $10 \%$ phycocyanin [109], but later other regulations came up that allowed differently processed spirulina food colorants containing not more than $2 \%$ [111] or up to $28 \%$ [112] phycocyanin (the latter is obtained in an aqueous extract obtained from spray-dried biomass).

According to the new European Union guideline on foods, food ingredients and flavorings with a secondary coloring effect (also termed 'coloring foodstuff' - reviewed by [113]), spirulina extract can be used as clean label without E-number in the European Union. As a consequence of these regulations, a 7-10fold expansion of the global market of spirulina-derived natural blue food colorants is expected. Spirulina is generally recognized as safe (GRAS) when used as food ingredient at quantities not higher than 0.5 to $3 \mathrm{~g}$ per serving [108]. In addition to use as human food, spirulina may be added to animal feed as well as additive.

\subsection{Health Promoting and Medicinal Effects}

Techuitlatl (blue gold) of the lake Texcoco in Mexico is in fact concentrated Arthrospira (spirulina) which has been known and consumed by Aztecs as a sort of dry cake since the pre-Columbian America (1300 A.D.) [114]. Similarly, different tribes in Sahara (especially Kanembu populations in Chad and Niger) used and still use the same species under the name dihé as healthy food rich in proteins and provitamin A [115], and recently FAO has also recognized spirulina as effective alternative to fight malnutrition and as animal feed [108]. Arthrospira or other cyanobacterial products (including those produced on the basis of Aphanizomenon flos-aquae - e.g., [116,117]) may be used as functional food due to their antioxidant, antimicrobial effects and fatty acid content $[13,61]$. There are several reports and reviews (e.g., $[5,13,115]$ ) about the potential health benefits (e.g., [118,119]) or toxicological studies of spirulina extraxts (proving its safe use as food, food colorant and food supplement).

However, in this Section the toxicology and potential health/medicinal effects and applications of phycobilins and phycobiliproteins are discussed. For further details about the roles of dietary phycocyanin [60,99] and phycobiliproteins [120] in animals and humans the readers are directed to the above-mentioned reviews $[60,99,120]$.

Medicinal studies with phycobilins should preferably use a single compound with verified purity and/or with stable and well-characterized composition. However, often this is not the case: several studies use 'spirulina' extract or dry powder in experiments, although the phycobilin and phycobiliprotein composition of these products greatly vary, not to speak about the low digestibility of algal cells and the presence of several other biologically active compounds in 
these extracts (e.g., Chls, carotenoids, lipids, etc.) (Fig. 7). Due to the presence of a complex mixture of different biologically active compounds, their different bioavailabilities, metabolization and biological effects as well as their synergistic or antagonistic effects it is difficult to clearly evaluate and compare literature data in such cases.

Therefore, studies dealing with the standardization of the growth conditions of organisms containing such commodities and of the commodities themselves are of great importance, and we decided to focus in this review on data dealing with purified phycobilins or phycobiliproteins.

Oxidative stress (ROS formation and lipid peroxidation), apoptosis and inflammatory processes are key players in many diseases, however, often several of them occur simultaneously. Therefore, the thematic grouping of the data below is only an attempt to overview literature data related to most important and characteristic effects of the different phycobiliproteins. Recent reviews summarizing in vitro and in vivo therapeutic potential of phycocyanin by separately discussing the different organs and cells are also available $[60,99]$.

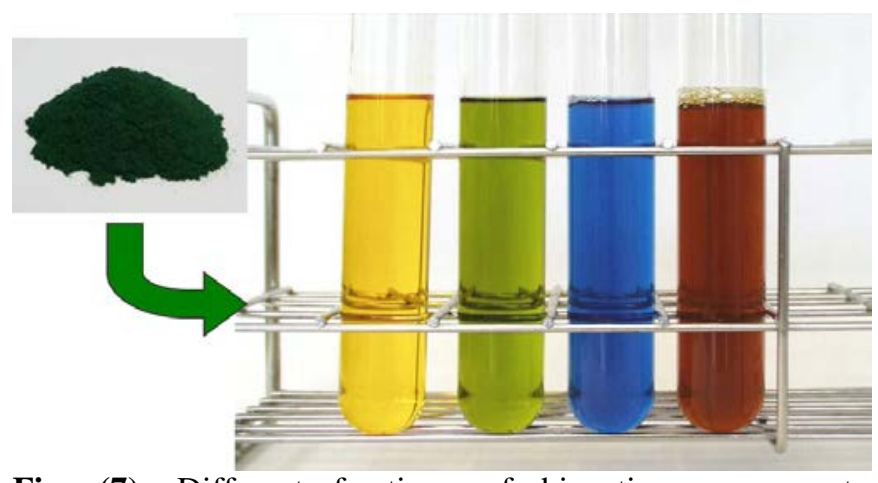

Fig. (7). Different fractions of bioactive components obtained from dried spirulina powder from left to the right: carotenoids (yellow fraction with $\beta$-carotene and zeaxanthin as main components), chlorophyll $a$ (green), phycocyanin (LinaBlue ${ }^{\circledR}$, blue), hot water extract from spirulina consisting of polysaccharides (brown) (photo courtesy to DIC Corporation).

\subsubsection{Bioavailability and Safety}

No cytotoxicity of phycocyanin was shown in vitro in mouse myeloma cell cultures incubated with phycocyanin, but toxicity could be induced by simultaneous photodynamic therapy (PDT), i.e., using laser irradiation of the same cells [121]. At the same time, colony forming assays with phycocyanin isolated from Microcystis and used for PDT have demonstrated that the cytotoxicity of phycocyanin is much lower on normal HL7702 liver cell lines than on HepG2 tumor cells [122]. Similarly to phycocyanin, no in vitro cytotoxicity of phycoerythrin was observed in the three human cell lines studied [123].

In these in vitro models, phycobiliproteins have been shown to enter the cells [124-127] and even mitochondria [122]. However, some of these studies treated the cells with saponin to permeabilize the cell membrane allowing the uptake of the polyclonal antibodies [122,124]. In addition, orally administered phycobiliproteins must suffer degradation in the gastrointestinal tract and, thus, probably their lower molecular weight metabolites are involved in the observed in vivo pharmacological effects [99]. For instance, such metabolites have been shown to cross the hematoencephalic-barrier where they exerted their neuroprotective effect [128]. It may be noteworthy to mention in this context that the in vitro antioxidant activity of phycocyanin was retained even after trypsin digestion [74].

The effective dosage of orally administered phycocyanin varies from 25 to $300 \mathrm{mg} \mathrm{kg}^{-1}$ in animal models of inflammation [99,129]. However, no toxicity, no adverse effects and no mortality have been reported during subchronic (5 mg phycoerythrin $\mathrm{kg}^{-1}$ b.w./day [123]) and acute toxicity tests of phycocyanin in rats $[123,130,131]$ and mice [130,132] even at 2000 [123], 3000 [130] or 5000 $[131,132] \mathrm{mg} \mathrm{kg}^{-1}$ oral administration. In addition to these no observed adverse effect levels (NOAEL) during oral feeding, intraperitoneal administration of $70 \mathrm{mg} \mathrm{kg}^{-1}$ [133] and even $200 \mathrm{mg} \mathrm{kg}^{-1}$ [134] phycocyanin also had no adverse effect in rats.

These data indicate that phycobiliproteins may be considered as potentially safe drugs and photosensitizers, although of course further metabolic, preclinical pharmacological and toxicological studies are needed to confirm this hypothesis. The pharmacokinetics and metabolism of phycobiliproteins must be also thoroughly characterized before eventual clinical trials.

\subsubsection{Antioxidant Effect}

Many diseases (i.e., neurodegenerative and inflammatory diseases, atherosclerosis, cancer, diabetes mellitus, reperfusion injury), and aging processes are induced and/or accompanied by oxidative stress. Unfortunately, in these cases the organism's own antioxidant defense system cannot counteract the excessive formation of free radicals, but disease may be prevented or the symptoms and/or effects may be alleviated by the therapeutic use of different antioxidants. The structure of phycobilins (especially phycocyanobilin) is similar to that of bilirubin, a potent antioxidant and ROS scavenger in vivo. This may explain - at least partly - the strong biological activity of phycobilin pigments and of the phycobiliproteins binding such pigments.

Most studies dealing with the antioxidant effects of the different phycobiliproteins were carried out using isolated phycocyanin (especially C-phycocyanin, a complex containing only phycocyanobilin) and/or its pigments, both extracted from Spirulina species, while much fewer studies concentrated on allophycocyanin (e.g., [100,135-137]) and/or phycoerythrin (e.g., [137-139]), the latter being used first of all as fluorescent dye (see Section 6.4).

Various in vitro and in vivo studies have confirmed that phycocyanin and phycocyanobilin are efficient scavengers of ROS [140]. For instance, phycocyanin scavenges hydroxyl [140-144], alkoxyl radicals [141], and peroxyl radicals [117,142-147], singlet oxygen [144,148], hydrogen peroxide [144,147], superoxide anions [144], hypochlorous acid [143,144,149] and reactive nitrogen species (RNS) such as peroxynitrite [144,150] and nitric oxide [151]. Phycobiliproteins (especially Se-containing phycocyanin) are also able to scavenge non-natural radicals (like e.g., 2,2-azinobis(3-ethylbenzothiazolin-6-sulphonic acid) $[152,153]$. Phycocyanin protected human erythrocytes 
[145] and rat liver microsomes against lysis caused by peroxyl and hydroxyl radicals [154] and inhibited lipid peroxidation in rat liver microsomes [141], in human and rat erythrocytes [116] and in carbon tetrachloride-induced rat liver in vivo [154]. Similarly, phycocyanin alleviated paraquat-induced acute lung injury in rats via alleviation of the earlier inflammation damage caused by paraquat-induced oxidative stress [155].

Most in vitro and in vivo studies have used purified phycobiliproteins, however, some studies separately tested and compared the antioxidant capacities of the functional pigment-protein complexes (e.g., phycocyanin) and of the chromophore pigment (e.g., phycocyanobilin) alone. For instance, in vitro studies have shown that phycocyanin isolated from Spirulina platensis is a more effective peroxynitrite scavenger than phycocyanobilin [150], while phycocyanobilin from Aphanizomenon flos-aquae proved to be a more effective peroxyl radical scavenger than phycocyanin from the same species [117]. In another in vitro study, phycocyanobilin was shown to be mostly responsible for the antioxidant activity of phycocyanin isolated from fresh or spray-dried Spirulina platensis against oxidation of methyl linoleate in a hydrophobic system or in phosphatidylcholine liposomes [156]. Obviously, the phycocyanobilin pigment(s) present in the phycobiliprotein complexes are involved in the process of ROS scavenging $[142,146,148,152,154,157]$ as demonstrated clearly by their radical assisted bleaching during this process $[142,148,154]$. For instance, singlet oxygen and peroxyl radicals are stabilized by oxidizing the double bond of the tetrapyrrole [142,144,149]. However, heterologously expressed allophycocyanin apoprotein and even its subunits were shown to inhibit hydroxyl radicals [135], and both phycocyanobilin and the recombinant apoprotein were shown to take part in the quenching of singlet oxygen [148]. Similarly, both the native phycocyanin and the recombinant phycocyanin apoprotein ( $\beta$ subunit) were able to scavenge peroxyl radicals and hydrogen peroxide and to protect erythrocytes from oxidative damage, although the latter was less effective [147].

Selenium-containing allophycocyanin also inhibited ROS generation, and, thus attenuated the oxidative stress induced by 2,2'azobis(2-amidinopropane) dihydrochloride in human erythrocytes [158]. Similarly, selenium-containing phycocyanin showed stronger antioxidant activity (superoxide and hydrogen peroxide radical-scavenging [152]) than phycocyanin in several in vitro assays [152,153].

Other works have shown that natural allophycocyanin [100] or phycocyanin [74,159] complexes isolated from Spirulina platensis have photodynamic effect [159] and can generate hydroxyl radicals in light (when excess excitation energy is absorbed but not properly allocated in them in the absence of the electron transport chain), but scavenge the same radicals in darkness (due to their antioxidant properties) [74,100]. Denaturation of the allophycocyanin [100] or phycocyanin [74] complexes by different agents lead to the disruption of the hydroxyl radical generating capacity in the light and at the same time increased the ROS scavenging activity, probably by exposing antioxidant parts of the complexes (i.e., the chromophores) to the environment containing the ROS. Trypsin digestion of the phycocyanin apoprotein demonstrated that the apoprotein itself also has antioxidant properties [74]. Methionine and cysteine $[160,161]$ (and other) amino acid residues of the protein may contribute to its antioxidant effect (for instance hypochloric acid scavenging) [149] as demonstrated also by studies on isolated phycocyanin peptides [161]. Red light illumination of phycocyanin caused bleaching of phycocyanobilin due to the singlet oxygen production induced by the irradiation of the bilin group [148]. On the other hand, blue light increased the in vitro scavenging effect of phycocyanin due to changes induced in the conformation of the protein (altering the localization of cysteine residues potentially involved in ROS scavenging) [160,161].

Taken together, these data show that both the open tetrapyrrole chromophores (e.g., $[142,146,148,157])$ and the phycobiliproteins (apoproteins and potentially their degradation products formed in the gastrointestinal tract, see Section 6.3.1) (e.g., [135,147,152]) have antioxidant effects by scavenging ROS and inhibiting lipid peroxidation [143]. In addition, phycocyanin can also chelate iron ions $[129,143]$, which are involved in many processes leading to the formation of free radicals and radical-mediated cell death. Therefore, phycobiliproteins may be used in the treatment of various conditions which are aggravated by ROS and in which iron is implicated like several neurodegenerative disorders (Alzheimer's and Parkinson's disease) [129]. Furthermore, the antioxidant activity of phycobiliproteins may also be associated with their chelating potential.

The strong antioxidant capacity of these compounds may explain, at least in part, their anti-inflammatory, anticancer and hepatoprotective effects. At the same time, their capacity to generate ROS upon light exposure may be used in PDT.

A new medicinal aspect of phycobiliproteins and their antioxidant properties is their potential use in anti-aging research (reviewed in [120]). For instance, phycoerythrin purified from Lyngbia and applied as dietary supplement improved the mean life span, moderated the decline in agingassociated physiological functions, enhanced stress tolerance, and also showed positive effects on an Alzheimer's disease model in a transgenic Caenorhabditis elegans CL4176 model $[137,138]$. This anti-aging activity of the phycobiliproteins was clearly associated with their significant and dose-dependent antioxidant (hydroxyl-, superoxide and other various radical scavenging) and metal $\left(\mathrm{Fe}^{2+}\right)$ chelating activity [137]. Interestingly, these systematic studies using the different phycobiliproteins isolated from Lyngbia have shown that phycoerythrin has the strongest hydroxyl and superoxide scavenging activity, while phycocyanin is the most potent $\mathrm{Fe}^{2+}$ chelator [137]. Cleary, the antioxidant activities of different phycobiliproteins (isolated from different organisms) and their chromophores have to be investigated and compared in different experimental settings.

\subsubsection{Photodynamic Therapy and Direct Anticancer Activities}

Several papers discuss the successful application of phycobiliproteins as photosensitizers (leading to the formation of reactive oxygen species and subsequent 
apoptosis) in PDT of different tumor cells [157,162] using different light sources (e.g., helium-neon laser, argon ion laser, etc.). In vitro experiments have shown that phycoerythrin incorporated to liposome carriers had enhanced cellular uptake and photodynamic effect resulting in apoptosis in the HepG2 human hepatocellular carcinoma cell line [163]. Phycocyanin isolated from Microcystis was found to be localized to mitochondria of the same HepG2 cell line in vitro, where it induced necrosis and apoptosis via mitochondria-dependent intrinsic pathway [122]. Phycoerythrin induced apoptosis in HeLa cell in vitro models when combined with PDT, and increased immunity and antioxidant ability also in Sarcoma-180 (S180) tumorbearing mice, in which it induced apoptosis by different cellular mechanisms (by increasing protease gene expression and tumor necrosis factor $\alpha$ secretion) [164]. Similarly, phycoeryhtrin and its subunits induced apoptosis and growth inhibition and a $\mathrm{G}_{0}-\mathrm{G}_{1}$ cell cycle arrest during PDT of mouse tumor cell line S180 and human liver carcinoma cell line SMC 7721 [165]. Both phycoerythrin and phycocyanin isolated from Porphyra yezoenis proved to be potential new photosensitizers for cancer PDT in the liver cancer cell line SMM C-7721 in vitro [166]. Phycocyanin-mediated PDT was shown to induce apoptosis and inhibit cell proliferation in a human breast adenocarcinoma (MCF-7) tumor model in mice and also in MCF-7 cell cultures [167]. Interestingly, in addition to its pro-apoptotic function (realized by the upregulation of pro-apoptotic proteins and downregulation of anti-apoptotic proteins in tumor cells) phycocyanin clearly had immune enhancing activity, which was only further enhanced by PDT [167]. This outlines the complex mechanism of PDT action on tumor cells. Due to its cytotoxic photosensibilization effect and specific binding to atherosclerotic plaques phycocyanin was shown to have a promising potential therapeutic use for atherosclerotic plaque localization and regression by PDT [121].

In addition to PDT, phycobiliproteins and phycobilins also have direct anticancer therapeutic effects which are often associated with the antioxidant and/or apoptosis inducing effects of these compounds. For instance, cancer cell proliferation was inhibited and apoptosis was induced in studies using (recombinant) phycocyanin in four different cancer cell lines [168]. Phycocyanin-induced apoptosis in a rat histiocytic AK-5 tumor cell line was shown to be possibly prompted by the generation of ROS and this apoptotic effect could be inhibited by ROS scavengers and the overexpression of Bcl-2, an apoptosis inhibitor [169]. Downregulation of the anti-apoptotic Bcl-2 was also shown to be one of the major molecular mechanisms of phycocyanin-induced apoptosis in both doxorubicinsensitive and resistant HepG2 hepatocellular carcinoma cell lines [125], human breast adenocarcinoma (MCF-7) cells [167], human HeLa cells [170], and in human chronic myeloid leukemia cell line K562 [124,171]. These in vitro studies have also shown that phycocyanin apparently enters the cytosol, where it exerts various other effects as well such as the release of cytochrome c from mitochondria to the cytosol, cleavage of poly(ADP) ribose polymerase $[124,125]$, activation of caspase expression, decrease in membrane potential, upregulation of pro-apoptotic proteins $[125,167,170]$. But other anticancer mechanisms, including c-myc protein, may be responsible for the growth inhibition of K562 chronic myelogenous leukemia-blast crisis cells [172]. Selenium-containing phycocyanin effectively induced apoptosis both in A375 human melanoma and MCF-7 human breast adenocarcinoma cells by depletion of the mitochondrial membrane potential [153]. Similarly, the antioxidant and anti-proliferative activity of phycocyanin was demonstrated in vitro by induction of apoptosis (arrest in $G_{0} / G_{1}$ phase and DNA fragmentation) in colon cancer (HT-29) and lung adenocarcinoma (A549) cells in vitro [151].

High doses of phycocyanin from Limnothrix had antioxidant activity [173] and anticancer properties in in vitro studies [174]. At the same time, its co-administration with topotecan (a currently available anticancer drug) potentially improved the efficacy of the latter to generate ROS and to activate caspases involved in apoptosis induction and apoptosis in LNCaP prostate cancer cell line [174]. Similarly, phycocyanin inhibited the growth of HeLa cells in vitro, and effectively induced apoptosis and promoted complement-mediated cytolysis when co-administered with all-trans-retinoic acid [175]. These data show that coadministration of phycobiliproteins with anticancer drugs may be effective in decreasing the needed drug concentrations, and thus, diminishing the harsh side effects of the latter in the patients, while keeping similarly efficient anticancer effects.

Phycocyanin induced in a dosage dependent manner the expression of cluster of differentiation 59, of apoptosisinducing factors and simultaneously declined the multiplication of HeLa cells as a kind of mitosis depressor, but did not affect these parameters in normal Chinese hamster ovary cells [176], which outlines its potential application as a novel anti-tumor therapeutic agent. Extracts of Spirulina platensis as well as its tetrapyrrolic components (phycocyanobilin and as a water-soluble Chl derivative, copper-chlorophyllin) substantially decreased the proliferation of experimental pancreatic cancer cells both in vitro (using several human pancreatic cancer cell lines) and in vivo (in xenotransplanted nude mice) [177].

The expression of critical early proteins involved in tumorigenesis was induced by the exposure of mouse skin to 12-O-tetradecanoyl-phorbol-13-acetate, however, the simultaneous presence of phycocyanin prevented these alterations in gene expression, further elucidating the large variety of mechanisms underlying the antitumor effects of this compound [178].

Most studies dealing with the direct anticancer effect of phycobiliproteins used phycocyanin, however, a mouse efficacy study of (recombinant) allophycocyanin showed remarkable inhibition of the S-180 carcinoma in mice [136 cf. 135].

On the other hand, phycocyanin showed antiapoptotic effect in vivo in rats with tributyltin-induced thymic atrophy due to its natural antioxidant and Fechelating capacity (see Section 6.3.2) which alleviated the oxidative stress mediated apoptosis in rat thymocytes in vivo [133].

Phycocyanin was effective in preventing galactoseinduced human lens epithelial cell (hLEC line SRA01/04) apoptosis in vitro through mitochondrial and unfolded 
protein response pathways, an effect that may have therapeutic implications in preventing cataract formation [179].

These data potentate phycobiliproteins as promising agents in prevention or treatment of various diseases including first of all cancer but also other diseases involving apoptotic processes. In addition, as a result of their photodynamic properties and binding capacity to cancer cells, phycobiliproteins may be suitable for tumor colocalization in vivo [121,151].

\subsubsection{Anti-inflammatory and Immunomodulatory effects}

Studies with so-called 'protein fraction' and isolated phycocyanin and phycoerythrin of Porphyra columbina have demonstrated that not the phycobiliproteins, but other factors are responsible for the immunomodulatory effect of the protein fraction [180]. However, there are several reports on the anti-inflammatory effect of phycobiliproteins. For instance, phycocyanin had anti-inflammatory effect similar to that of non-steroidal drugs and was, thus, effective in decreasing edema index in glucose-oxidase induced inflammation in mouse paw model [141], in carrageenaninduced rat paw edema model (both in intact and adrenalectomized rats) [130], arachidonic acid- and tetradecanoylphorbol acetate-induced ear edema model in mice $[130,181,182]$, and had inhibitory effect in the cotton pellet granuloma test in the rat axilla [130]. Topical administration of phycocyanin containing liposomes resulted in anti-inflammatory activity in croton-oil-induced or arachidonic acid-induced ear edema models in rats [183].

Phycocyanin also showed anti-inflammatory effect in a zymosan-induced experimental arthritis model in mice [184], in acetic acid induced colitis in rats [185] and in carrageenan-induced thermal hyperalgesia model where both its pre- or post-administration influenced nociception (rat paw withdrawal) showing its additional antihyperalgesic activity in this model [186]. Phycocyanin also inhibited allergic inflammatory response in a dose dependent manner in ovalbumin-induced edema model in mice as well as in other in vivo and in vitro models probably due to its inhibitory effect on histamine release from mast cells [187]. In vitro studies in lipopolysaccharide-stimulated RAW 264.7 macrophages [188] or BV-2 microglial cells [189] indicated that phycocyanin inhibits nitrite production, tumor necrosis factor formation and NF-кB (nuclear factor kappa-lightchain-enhancer of activated B cells) activation [188], decreases the cytotoxicity and inhibits the expression of inflammation-related genes [189]. In addition, the observed anti-inflammatory effects are probably due, at least in part, to the antioxidant and ROS scavenging effects of phycocyanin (see Section 6.3.2) [130,184,185], to its inhibitory effects on arachidonic acid metabolism and cytokine production, on tumor necrosis factor formation [184,188], leukotriene $B_{4}$ formation [181], and on prostaglandin E2 production and phospholipase A2 activity [182]. In vitro studies using isolated enzyme assays and whole blood assays have shown that even very low (nanomolar) concentrations of phycocyanin selectively inhibit cyclooxygenase type 2 (COX-2) [190] which is upregulated during inflammation and cancer (especially breast cancer cells), and which in addition may also reduce prostaglandin E2 production [191].
This inhibitory effect may explain - at least in part - the anti-tumor, hepatoprotective, anti-arthritic and antiinflammatory effects of phycocyanin, as COX-2 inhibitors induce apoptosis in cancer cells and also in cells involved in inflammation (e.g., in lipopolysaccharide-stimulated RAW 264.7 mouse macrophage cell lines in vitro [191]). Interestingly, the apoprotein part, and not the phycocyanobilin pigments, seemed to be responsible for the selective inhibition of COX-2 [190]. Works dealing with murine macrophage cell line J774A.1 have demonstrated that phycocyanin decreased the production of lipopolysaccharideinduced ROS, but stimulated the secretion of inflammatory cytokines and boosted immunomodulation performance [192]. Posttreatment with phycocyanin alleviated lung edema and inflammation in a rat model of acute lung injury induced by intratracheally administered lipopolysaccharide by decreasing oxidative stress, and down- and upregulating pro- and anti-apoptotic proteins, respectively [193].

Dietary supplementation with phycocyanin was effective in reducing the tinnitus induced by intraperitoneally administered salicylate by downregulation of the expression of genes involved in inflammation (such as N-methyl Daspartate receptor, tumor necrosis factor- $\alpha$, interleukin- $1 \beta$, and cyclooxygenase type 2) in the cochlea and inferior colliculus of mice [194].

Experiments with mice orally immunized with antigen (ovalbumin)-entrapped biodegradable microparticles showed that previous administration of phycocyanin enhanced secretary IgA antibody response and functions of the mucosal immune system while reduced the allergic inflammation by the suppression of antigen-specific IgE antibody [195]. Phycocyanin and phycocyanobilin have the potential to boost $\mathrm{T}$ regulatory cell activity [196], and thus may have therapeutic potential in the management of inflammatory disorders and autoimmune or allergic syndromes [197].

\subsubsection{Hepatoprotective and Nephroprotective Effects}

Single-dose intraperitoneal administration of phycocyanin significantly reduced the carbon tetrachloride $\left(\mathrm{CCl}_{4}\right)$ and $R$-(1)-pulegone-induced hepatotoxicity in rats by providing protection to liver enzymes [134]. This effect was probably obtained by lowering the biotransformation of the hepatotoxins into toxic intermediates and the alleviation of oxidative stress by antioxidant activity (ability to scavenge haloalkane free radicals). Phycocyanin alleviated the carbon tetrachloride induced hepatocyte damage both in vitro (in L02 human hepatocyte cell line [198]) and in vivo in mice [198] or rats [199] by protecting the cells from free radical damage and oxidative stress [198,199], and inflammatory infiltration [198]. Similarly, intraperitoneal preadministration of phycocyanin effectively reduced the necrosis and inflammation during intraperitoneal galactosamine-induced hepatitis [200].

In other studies, orally administered phycoerythrin [201] or phycocyanin [202] along with intraperitoneally added carbon tetrachloride [201] or Na-oxalate [202] had similarly an ameliorative effect on hepatic [201] and renal [201,202] toxiticy symptoms in rats. Phycocyanin may also be useful to fight against oxalate-mediated nephronal impairment due to oxidative stress [202]. A mixture of 
Arthrospira maxima phycobiliproteins as well as purified phycocyanin from the same species [203] and a mixture of phycobiliproteins (rich in phycoerythrin) and extracted from Pseudanabaena tenuis [204] protected rat renal cells against $\mathrm{HgCl}_{2}$-induced oxidative stress and cellular damage. Phycocyanin significantly decreased Kupffer cell phagocytosis and oxidative stress upon colloidal carbon uptake in isolated perfused mouse liver models [205].

The pharmacological effect is often attributed to the tetrapyrrole and to some extent bilirubin biotransformations as well as metabolic (dietary protein) actions of the phycoerythrin apoprotein [201]. Soni et al. [201] clearly demonstrated that the chromophore part (phycobilin pigment) got absorbed in the gut and metabolized leading to increased bilirubin concentration. Intragastric intubation of rats with gibberellic acid (a dangerous pesticide) and simultaneously administered phycocyanin improved the antioxidant defense system, liver enzymes and hepatocyte structure when compared to animals treated only with gibberellic acid [206].

Similarly, it has been shown that phycocyanobilin binds human serum albumin with high affinity and competes with bilirubin for binding on this protein, indicating that the pharmacokinetics of phycocyanobilin may be influenced by bilirubin plasma concentration [207].

Phycocyanobilin pigments metabolized to biliverdin/bilirubin homologs (phycocyanorubin) by for instance rat liver biliverdin reductase [208] inhibited NADPH oxidase activity (already at micromolar concentrations) [209]. Therefore, it has been hypothesized that their joint administration with genistein (a soy isoflavone) may prevent hepatic fibrosis in at-risk subjects [210].

Thioacetamide-induced hepatic encephalopathy of rats could be also ameliorated by co-administration of phycocyanin and subsequently improved antioxidant defense responses [211].

Intraperitoneally added phycocyanin alleviated the oxidative stress and nephrotoxicity caused by intraperitoneally administered cisplatin in mice, probably due to the ROS, RNS and hypochlorous acid scavenging activity of phycocyanin [144]. Similarly, due to its antioxidant activity, orally pre-administered single-dose phycocyanin protected the integrity of renal cells during nephrotoxicity induced by intraperitoneal oxalate injections in experimentally induced urolithic rats [212]. Phycocyanin efficiently protected the renal epithelial cell line (MDCK) against oxalate-mediated oxidative stress, lipid peroxidation and mitochondrial dysfunctions outlining its potential in treating oxidative stress-associated diseases like urolithiasis [213].

\subsubsection{Neuroprotective Effects}

Phycocyanin was shown to prevent potassium/serum deprivation-induced apoptosis in rat cerebellar granule cell cultures probably due to its antioxidant effect [214], and may be, therefore, have some potential in treating Alzheimer's and Parkinson's diseases. Similarly, orally administered phycocyanin reached the brain parenchyma (and thus, it or its metabolites crossed the hemato-encephalic-barrier) in sufficient concentrations to reduce the neurotoxic impact (microglial and astroglial activation) of the excitotoxin kainine in rat hippocampus [128].

Phycocyanin may be also used as neuroprotector to treat experimental autoimmune encephalomyelitis in rats and multiple sclerosis (and other neurodegenerative disorders) by its antioxidant capacity and by inducing regulatory $\mathrm{T}$ cell response in peripheral blood mononuclear cells in humans [196].

Similarly, phycocyanin was shown to have neuroprotective effect against global cerebral ischemia/reperfusion (stroke) injury in gerbils both prophylactically or therapeutically by decreasing infarct volume, protecting against hippocampus neuronal cell death via its antioxidant activity (prevention of lipid peroxidation) [215]. Its neuroprotective effect was further demonstrated in vitro in tert-butylhydroperoxide-induced oxidative injury in SH-SY5Y neuroblastoma cells, in pressure/reperfusion induced transient ischemia in rat retinas and in calcium/phosphate induced impairment of isolated rat brain mitochondria where phycocyanin neuroprotection was realized by protecting mitochondria and reducing oxidative stress [216]. In SH-SY5Y neuroblastoma cells phycocyanin also exerted neuroprotective effect against iron-induced toxicity due to its chelating potential, and, thus, a decrease in iron-mediated ROS formation and neuropathology [129].

Taken together, and especially based on the activity of phycocyanobilin as antioxidant on the oxidative stress caused by peroxynitrite radicals and on NADPH oxidase, a key molecule contributing to the pathogenicity of activated brain microglia, oral phycocyanobilin may be useful in the treatment and/or prevention of various neurodegenerative disorders [217,218]. However, its anti-inflammatory and immuno-modulatory properties could also contribute to its neuroprotective properties [189,215].

\subsubsection{Other Miscellaneous Medicinal Effects}

Phycocyanin has been identified and characterized as a novel and very potent antiplatelet agent (preventing the aggregation of platelets in vitro even at nanomolar concentrations) for treatment of arterial thromboembolism $[219,220]$. In addition to the confirmation of its scavenging activity on hydroxyl radicals released from activated platelets [219], it was also shown to inhibit several important processes leading to platelet aggregation [219,220]. Phycocyanin also exhibited profibrinolytic effect in calf pulmonary arterial endothelial cells which further outlines its potential use in prophylaxis against thrombotic vascular disorders [221].

Purified phycoerythrin protected human fibroblasts from $\mathrm{KMnO}_{4}$-mediated DNA damage [123]. Phycocyanin has been shown to be a potent wound-healing agent in vivo and in vitro that may be even used to heal internal wounds such as ulcer [222]. An isolated cysteine-rich cyanopeptide from Spirulina phycocyanin induced human lung fibroblast (TIG 3-20) migration to wounded area in an in vitro cell scratch injury assay suggesting its role in fibroblast proliferation and migration, and thus in wound healing and atherosclerosis among others [161].

Phycoerythrin also attenuated diabetic complications and Cu-mediated lipoprotein oxidation in streptozotocinnicotinamide-induced type 2 diabetic rats by reducing the 
oxidative stress and the oxidized low-density lipoproteintriggered atherogenesis [139]. Phycocyanin protected the pancreatic islets from alloxan injury via different mechanisms (promoting glycogen synthesis in the liver, preventing oxidative stress in the liver, kidney and pancreas, decreasing cholesterol and triglyceride levels in the serum and the liver) showing the potential of this compound to prevent diabetes [132].

Similarly, oral administration of phycocyanin (300 $\mathrm{mg} \mathrm{kg}^{-1}$ for 10 weeks) and phycocyanobilin $\left(15 \mathrm{mg} \mathrm{kg}^{-1}\right.$ for 2 weeks) in $d b / d b$ mice, a rodent model for type 2 diabetes had clearly antioxidant properties preventing the animals from oxidative stress and renal dysfunction by various mechanisms including NADPH oxidase, thus, offering a novel and feasible therapeutic approach to prevent diabetic nephropathy [223]. The fact that phycocyanobilin had similar protective effect indicates that it may be responsible for this effect of the phycocyanin complex. In vitro models have shown that phycocyanin protected rat insulinoma beta cells (INS-1E) against human islet amyloid popypeptide (hIAPP) induced apoptosis by attenuating oxidative stress and modulating different signaling pathways [224]. As hIAPP aggregation plays an important role in the loss of insulin-producing pancreatic beta cells, these results outline the potential therapeutic importance of phycocyanin in the treatment or prevention of diabetes.

In vitro experiments (on EA.hy926 endothelial cells) and in vivo experiments in mice have shown that phycocyanobilin (and Spirulina extracts) activated the atheroprotective heme oxygenase-1 (Hmox1) involved in the generation of bilirubin, a potent antioxidant, and also modulated other important markers of oxidative stress and endothelial disfunction (e.g., NADPH oxidase subunit) [225].

Oral administration of phycocyanin decreased the serum cholesterol concentration and atherogenic index, and thus, had a strong hypocholesterolemic effect in rats fed on high-cholesterol diet [226]. Similarly, chronic consumption of Se-rich or normal Spirulina phycocyanin powerfully prevented the development of atherosclerosis by decreasing oxidative stress and NADPH oxidase expression and improvement of the serum lipid profile in hamsters fed on atherogenic diet [209]. These data outline the potential of phycocyanin and phycocyanobilin in the reduction of atherosclerotic disease.

Phycocyanin also had a preventive action on naphthalene and galactose [227] or Na-selenite [228] induced cataract models in rats due to its antioxidant and ROS scavenging activity [227] and, thus, its ability to prevent/alter secondary changes [228].

Similarly, it stimulated the lymphocyte enzymatic antioxidant defense system of nuclear power-plant workers upon irradiation, outlining its potential to protect occupationally exposed persons from radiation [229].

Phycocyanin also had cardioprotective effects. It alleviated the doxorubicin-induced oxidative stress and apoptosis of cardiomyocytes isolated from adult rat hearts [230] and attenuated the ischemia-reperfusion-induced myocardial injury and disfunction (enhanced the recovery of heart function and decreased the infarct size) in isolated perfused Langendorff rat heart model via its antioxidant, anti-apoptotic and signaling pathway modulatory effects [231].

Confocal immunofluorescence and immunoblot analyses have demonstrated that phycocyanin can enter B16F10 melanoma cells in vitro, where it exerts dual antimelanogenic effect, resulting in suppression of melanin synthesis [127]. This effect may be used in biomedicine and cosmetics for skin whitening (e.g., in case of abnormal hyperpigmentation).

Phycocyanin inhibited the expression of the acetylaminofluorene-induced multidrug resistance protein (MDR1) in the mouse macrophage cell line RAW 264.7 in vitro by scavenging ROS [232] and in the liver of albino mice in vivo by interfering at the level of ROS generation, Akt (protein kinase B) phosphorylation and NF- $\mathrm{KB}$ translocation [233]. The same mechanisms (downregulation of ROS and COX-2 pathways via the involvement of NF- $\mathrm{BB}$ and activator protein 1 - AP-1, inhibition of MDR1) were confirmed in HepG2 human hepatocarcinoma cell line in relation to prevention of doxorubicin resistance by phycocyanin [126]. These data suggest that phycocyanin may be used to overcome drug and xenobiotic resistance in cellular systems [232] and to increase the sensitivity of cells to drugs (e.g., doxorubicin) [126]. It is noteworthy to mention, that phycocyanin did not interfere with the antineoplastic activity of the drug in human ovarian cancer cells $[60,230]$.

Pre-, post- or simultaneously administered allophycocyanin was also shown to have antiviral effect: it delayed viral RNA synthesis in infected cells and neutralized the enterovirus 71-induced cytopathic (apoptotic) effect in human rhabdomyosarcoma and African green monkey kidney cell models [234].

\subsection{Other Industrial Application of Tetrapyrrole Derivatives}

Phycobilisomes are genuinely organized photosynthetic antennae the chromophore components of which transfer the absorbed light energy towards their acceptors (and finally to Chl $a$ in reaction centre cores) in a highly efficient manner. However, when extracted to aqueous buffer, phycobilisomes disintegrate, and the phycobiliproteins, and their bound chromophores lose their acceptors, and get rid of the absorbed light energy by intensive fluorescence emission. This, along with the fact that many chromophores are present in the hexameric phycobiliprotein complexes, explains the excellent fluorescence properties (extremely high quantum yields and molar extinction coefficients) of the pigments of phycobiliproteins when compared to other fluorophores [13]. The quantum yields (efficiencies) of phycoerythrin and allophycocyanin are 0.82 and 0.68 , respectively, their extinction coefficients are 1,960,000 and $700,000 \mathrm{~cm}^{-1} \mathrm{M}^{-1}$, respectively [235]. Another advantage of their use as fluorescent dyes is that they can be excited and emit in the red end of the visible spectrum, interfering this way less with other biological compounds and/or fluorescent dyes [61]. In addition, phycobiliproteins also have large Stokes shifts (of approx. $80 \mathrm{~nm}$ without significant interference with Rayleigh or Raman scatter or with other fluorescing compounds) 
[61,73], and their apoprotein chains contain amino and carboxyl groups that enable their conjugation with other molecules [13]. Their quantum yields do not depend on $\mathrm{pH}$ [61], however, monomerization of phycobiliprotein hexamers and denaturation of the apoproteins result in strong decrease of the fluorescence intensity of the chromophores.

The first fluorescence probes using phycobiliproteins were orange-red colored phycoerythrin-immunoglobulin, phycoerythrin-protein A, and phycoeryhtrin-avidin conjugates detectable at femtomol concentrations due to the high fluorescence yield of the chromophores [236]. Due to their advantageous properties, phycobiliproteins (especially phycoerythrin and allophycocyanin, and to a lesser extent cryptophyte-derived phycobiliproteins [237], and energy transfer tandem dyes of phycoerythrin and allophycocyanin [238]) are nowadays routinely used as preferred fluorescent dyes for applications that require either sensitivity or simultaneous multicolor detection [13,20,61,239-243]. These include clinical and immunological analyses, where phycobiliproteins are used to label antibodies, receptors or other molecules in fluorescence microscopy, immunolabelling, diagnostics, and fluorescence-activated cell sorters (flow cytometry). Unfortunately, the high molecular weight of phycobiliproteins (approx. $200 \mathrm{kDa}$ ) hinders their diffusion into cells of interest, and, thus limits their applicability [73]. However, discussing these data is beyond the scope of this review and is discussed in detail elsewhere [61].

\section{CONCLUSIONS AND FUTURE PERSPECTIVES}

The consumers' increasing demand in natural colorings represents a major problem for the food industry in case of green and blue hues and especially their watersoluble forms. These are nowadays available only as watersoluble Chl derivatives (E140ii and E141ii) facing compositional and nomenclatural problems and strict reevaluation in the European Union [7,244] and limited acceptance in the United States $[80,245]$. Therefore, the use of different phycobilins or phycobilin-containing products such as phycobiliproteins or spirulina extracts as coloring food will probably gain more importance in the upcoming years.

However, to achieve this goal, the thermal, light and $\mathrm{pH}$ stability of the pigments and especially the phycobiliproteins, as well as their aqueous stability, and their alcohol resistance and shelf life have to be improved [61]. The rheological properties [246] and the interactions of the pigments with other substances and matrices like for instance preservatives $[94,247]$ all need further studies. Similarly, the cultivation, extraction [75] and purification procedures yielding such commodities also need standardization and further optimization.

For low-cost industrial production of phycobilins (and to a lesser extent Chls and also carotenoids) usually outdoor, photoautotrophic growth of cyanobacterial and/or red algal cultures are used in tropical and subtropical regions (Fig. 5). However, myxotrophic and heterotrophic algal cultures (the latter using for instance Galdieria sulphuraria $[13,248]$ ) may be also considered, as well as recombinant protein production in different organisms [13] (e.g., Escherichia coli
[135,147,249,250], Streptomyces [251] and Chlamydomonas reinhardtii [252]). Photobioreactors of different types (e.g., designed flat-type photobioreactor [253], airlift tubular photobioreactor [254]) are being developed for industrial scale production to simultaneously enhance phycocyanin production and $\mathrm{CO}_{2}$ fixation [253]. Other perspective future directions include the valorization of industrial polluting byproducts (e.g., beet vinasse, a byproduct of molasses fermentation factories) for Spirulina cultivation [254], and the use of Spirulina cultures to fix and, thus, decrease $\mathrm{CO}_{2}$ emissions from power plant flue gas [192,253].

1.Concerning the health and medicinal effects of phycobiliproteins and phycobilins, strictly, consistently and carefully planned and evaluated long-term experiments are needed to assess the relevance of the different in vitro data in vivo in humans. To this aim, the mechanisms of digestion, absorption, transport, metabolization, potential toxicity and the interactions of these various compounds and processes need to be better understood.

At the same time, the therapeutic potentials of phycobiliproteins and phycobilins were in general tested for phycocyanin and/or phycocyanobilin obtained from Spirulina, while phycobiliproteins and phycobilins (e.g., also allophycocyanin [255] and phycoerythrin [77,8588,90,164]) obtained from other cyanobacteria (e.g., Anabaena marina [92], Aphanizomenon flos-aquae [117], Limnothrix [173,174], Lyngbya [142], Myxosarcina concinna [255], Microcystis [122], Oscillatoria tenuis [151], Phormidium fragile [256], Phormidium tenue [139,142,201] or Pseudanabaena tenuis [204]) or red algae (Corallina elongata [86], Heterosiphonia japonica [87], Polysiphonia urceolata [85,88], Porphyra yezoensis [166], Porphyra haitanensis [164], Porphyridium purpureum [76] or Porphyridium cruentum [90]) and other species may also have similar (or other) potential, and thus, require further studies. Isolated peptides of phycocyanins may also have therapeutical potential as they had antioxidant activity and inhibited the ROS induced DNA damage in vitro [161]. Similarly, studies showing the high potency of coadministration of phycobiliproteins with low doses of existing anticancer or other drugs may open up new perspectives in the prevention and/or treatment of various diseases. Studies aimed at microencapsulation of phycocyanin [183,257] and phycoerythrin [163] in alginate and chitozan as coating materials [257] and in liposomes $[163,183]$ as well as optimizing its release profile are already going on. This clearly outlines the great interest of the of the pharmaceutical industry in these compounds. Several patents and constantly developed expensive phycobiliproteinconjugated fluorescent dyes for flow cytometry and antibodies for immunolabelling show the great potential of these products in these other areas as well $[61,258]$.

Clearly, in addition to their role in photosynthetic light capture in some photosynthetic pro- and eukaryotes, phycobilins and phycobiliproteins have also the potential as healthy natural food colorings or coloring food, as fluorescent dyes and also in medicine. Further research and the upcoming years will tell us how much and in which forms they can be best used by the food industry and medicine. 


\section{CONFLICT OF INTEREST}

The authors confirm that this article content has no conflict of interest.

\section{ACKNOWLEDGEMENTS}

We apologize to all authors whose works were not cited due to space limitations. We are grateful to DIC Corporation for providing figures about spirulina and LinaBlue ${ }^{\circledR}$ and to Joe Scott (College William and Mary, Virginia, USA) for providing the electron micrograph about Compsopogon. We are grateful to the editor and the anonymous reviewers for their valuable comments and suggestions. The Faculty of Biochemistry, Biophysics and Biotechnology of Jagiellonian University is a partner of the Leading National Research Center (KNOW) supported by the Ministry of Science and Higher Education. This work was supported by the Janos Bolyai Research Scholarship of the Hungarian Academy of Sciences (to K.S.).

\section{ABBREVIATIONS}

Chl = chlorophyll

COX-2 = cyclooxygenase type 2

$\mathrm{NF}-\kappa \mathrm{B}=$ nuclear factor kappa-light-chain-enhancer of activated B cells

PDT $=$ photodynamic therapy

PROTO IX = protoporphyrin IX

PSII = photosystem II

RNS $=$ reactive nitrogen species

ROS $=$ reactive oxygen species

\section{REFERENCES}

[1] Esenbeck, N. Über einen blau-rothen Farbstoff, der sich bei der Zersetzung von Oscillatorien bildet. Liebigs Ann. Chem., 1836, 17(1), 75-82.

[2] Kützing, F.T. Phycologia generalis, oder Anatomie, Physiologie und Systemkunde der Tange; F.A. Brockhaus: Leipzig, 1843.

[3] Stokes, G.G. Ueber die Metallreflexion an gewissen nichtmetallischen Substanzen. Ann. Phys., 1854, 167(2), 300-314.

[4] Sorby, H.C. On the characteristic colouring-matters of the red groups of algae. J. Linn. Soc. London Bot., 1875, 15(81), 34-40.

[5] Schoefs, B. In: Handbook of Analysis of Active Compounds in Functional Foods; Nollet, L.; Toldrá, F., Eds. CRC Press: Boca Raton, London, New York, 2012; pp. 665-685.

[6] Solymosi, K.; Latruffe, N.; Morant-Manceau, A.; Schoefs, B. In: Colour Additives for Foods and Beverages; Scotter, M.J., Ed. Woodhead Publishing-Elsevier: Oxford, 2015; pp. 3-34

[7] Solymosi, K.; Mysliwa-Kurdziel, B. Chlorophylls and their derivatives used in food industry and medicine. Mini-Reviews Med. Chem. IN THIS ISSUE TO BE UPDATED

[8] Schoefs, B. Plant pigments: Properties, analysis, degradation. Adv. Food Nutr. Res., 2005, 49, 41-91.

[9] Borowitzka, M.A. High-value products from microalgae - their development and commercialisation. J. Appl. Phycol., 2013, 25(3), 743-756.

[10] Beale, S.I. Biosynthesis of phycobilins. Chem. Rev., 1993, 93(2), 785-802.

[11] Glazer, A.N. Light harvesting by phycobilisomes. Annu. Rev. Biophys. Biophys. Chem., 1985, 14, 47-77.

[12] Houghton, J.D. In: Natural Food Colorants SE - 6; Hendry, G.A.F.; Houghton, J.D., Eds. Springer: Dordrecht, 1996; pp. 157196.

[13] Eriksen, N.T. Production of phycocyanin - A pigment with applications in biology, biotechnology, foods and medicine. Appl. Microbiol. Biotechnol., 2008, 80(1), 1-14.

[14] Sidler, W.A. In: The Molecular Biology of Cyanobacteria, Advances in Photosynthesis; Bryant, D., Ed. Kluwer Academic Publishers: Dordrecht, 1994; Vol. 1, pp. 139-216.

[15] Stadnichuk, I.N.; Krasilnikov, P.M.; Zlenko, D.V. Cyanobacterial phycobilisomes and phycobiliproteins. Microbiology, 2015, 84(2), 101-111.

[16] Tandeau de Marsac, N. Phycobiliproteins and phycobilisomes: the early observations. Photosynth. Res., 2003, 76(1-3), 193-205.

MacColl, R. Cyanobacterial phycobilisomes. J. Struct. Biol., 1998, 124(2-3), 311-334.

[18] Wedemayer, G.J.; Kidd, D.G.; Wemmer, D.E.; Glazer, A.N. Phycobilins of cryptophycean algae. Structures of novel bilins with acryloyl substituents from phycoerythrin 566. J. Biol. Chem., 1991, 266(8), 4731-4741.

[19] Wedemayer, G.J.; Kidd, D.G.; Wemmer, D.E.; Glazer, A.N. Phycobilins of cryptophycean algae. Occurrence of dihydrobiliverdin and mesobiliverdin in cryptomonad biliproteins. J. Biol. Chem., 1992, 267, 7315-7331.

[20] Scheer, H.; Zhao, K.-H.H. Biliprotein maturation: The chromophore attachment. Mol. Microbiol., 2008, 68(2), 263-276.

[21] Singh, N.K.; Sonani, R.R.; Rastogi, R.P.; Madamwar, D. The phycobilisomes: an early requisite for efficient photosynthesis in cyanobacteria. EXCLI J., 2015, 14, 268-289.

[22] Scheer, H. Biliproteins. Angew. Chem. Int. Ed., 1981, 20(3), 241261.

[23] Duerring, M.; Huber, R.; Bode, W.; Ruembeli, R.; Zuber, H. Refined three-dimensional structure of phycoerythrocyanin from the cyanobacterium Mastigocladus laminosus at $2.7 \AA$. J. Mol. Biol., 1990, 211(3), 633-644.

[24] Mochizuki, N.; Tanaka, R.; Grimm, B.; Masuda, T.; Moulin, M.; Smith, A.G.; Tanaka, A.; Terry, M.J. The cell biology of tetrapyrroles: a life and death struggle. Trends Plant Sci., 2010, 15(9), 488-498.

[25] Brzezowski, P.; Richter, A.S.; Grimm, B. Regulation and function of tetrapyrrole biosynthesis in plants and algae. BBA Bioenergetics, 2015, 1847(9), 968-985.

[26] Czarnecki, O.; Grimm, B. Post-translational control of tetrapyrrole biosynthesis in plants, algae, and cyanobacteria. J. Exp. Bot., 2012, 63(4), 1675-1687.

[27] Fujita, Y.; Tsujimoto, R.; Aoki, R. Evolutionary aspects and regulation of tetrapyrrole biosynthesis in cyanobacteria under aerobic and anaerobic environments. Life, 2015, 5(2), 1172-1203.

[28] Richter, A.S.; Grimm, B. Thiol-based redox control of enzymes involved in the tetrapyrrole biosynthesis pathway in plants. Front. Plant Sci., 2013, 4, 371.

(29] Yin, L.; Bauer, C.E. Controlling the delicate balance of tetrapyrrole biosynthesis. Philos. Trans. R. Soc. Lond. B. Biol. Sci., 2013, 368(1622), 20120262.

[30] Tanaka, R.; Kobayashi, K.; Masuda, T. Tetrapyrrole metabolism in Arabidopsis thaliana. Arabidopsis Book, 2011, 9(9), e0145.

[31] Moulin, M.; Smith, A.G. Regulation of tetrapyrrole biosynthesis in higher plants. Biochem. Soc. Trans., 2005, 33(4), 737-742.

[32] Tanaka, R.; Tanaka, A. Tetrapyrrole biosynthesis in higher plants. Annu. Rev. Plant Biol., 2007, 58(1), 321-346.

[33] Chen, M. Chlorophyll modifications and their spectral extension in oxygenic photosynthesis. Annu. Rev. Biochem., 2014, 83(1), 317-340.

[34] Masuda, T. Recent overview of the Mg branch of the tetrapyrrole biosynthesis leading to chlorophylls. Photosynth. Res., 2008 , 96(2), 121-143.

[35] Masuda, T.; Fujita, Y. Regulation and evolution of chlorophyll metabolism. Photochem. Photobiol. Sci., 2008, 7(10), 1131-1149.

[36] Rebeiz, C.A. Chlorophyll Biosynthesis and Technological Applications; Springer: Dordrecht, 2014.

[37] Beale, S.I. In: The Molecular Biology of Cyanobacteria; Bryant, D., Ed. Kluwer Academic Publishers: Dordrecht, 1994; Advances in Photosynthesis Vol. 1, pp. 519-558.

[38] Brown, S.B.; Holroyd, J.A.; Troxler, R.F.; Offnert, G.D. Bile pigment synthesis in plants. Biochem. J., 1981, 194(1), 137-147.

[39] Beale, S.I.; Chen, N.C. N-methyl mesoporphyrin IX inhibits phycocyanin, but not chlorophyll synthesis in Cyanidium caldarium. Plant Physiol., 1983, 71(2), 263-268.

[40] Troxler, R.F.; Brown, A.; Lester, R.; White, P. Bile pigment formation in plants. Science, 1970, 167(3915), 192-193.

[41] Troxler, R.F.; Dokos, J.M. Formation of carbon-monoxide and bile pigment in red and blue-green-algae. Plant Physiol., 1973, 51(1), 72-75.

[42] Troxler, F.; Brown, S.; Brown, B. Bile pigment synthesis in plants. J. Biol. Chem., 1979, 254(9), 3411-3418.

[43] Mantle, T.J. Haem degradation in animals and plants. Biochem. Soc. Trans., 2002, 30, 630-633.

[44] Shekhawat, G.S.; Dixit, S.; Verma, K.; Nasybullina, E.I.; 
Kosmachevskaya, O.V; Topunov, A.F. Heme oxygenase: enzyme with functional diversity. J. Stress Physiol. Biochem., 2011, 7(1), 88-94.

[45] Beale, S.I.; Cornejo, J. Enzymatic heme oxygenase activity in soluble extracts of the unicellular red alga, Cyanidium caldarium. Arch. Biochem. Biophys., 1984, 235(2), 371-384.

[46] Rhie, G.; Beale, S.I. Biosynthesis of phycobilins. Ferredoxinsupported NADPH-independent heme oxygenase and phycobilinforming activities from Cyanidium caldarium. J. Biol. Chem., 1992, 267(23), 16088-16093.

[47] Rhie, G.E.; Beale, S.I. Phycobilin biosynthesis: Reductant requirements and product identification for heme oxygenase from Cyanidium caldarium. Arch. Biochem. Biophys., 1995, 320(1), 182-194.

[48] Zhang, X.; Migita, C.T.; Sato, M.; Sasahara, M.; Yoshida, T. Protein expressed by the ho2 gene of the cyanobacterium Synechocystis sp. PCC 6803 is a true heme oxygenase. Properties of the heme and enzyme complex. FEBS J., 2005, 272(4), 10121022

[49] Gohya, T.; Zhang, X.; Yoshida, T.; Migita, C.T. Spectroscopic characterization of a higher plant heme oxygenase isoform- 1 from Glycine max (soybean) - coordination structure of the heme complex and catabolism of heme. FEBS J., 2006, 273(23), 53845399.

[50] Dammeyer, T.; Frankenberg-Dinkel, N. Function and distribution of bilin biosynthesis enzymes in photosynthetic organisms. Photochem. Photobiol. Sci., 2008, 7(10), 1121-1130.

[51] Rockwell, N.C.; Martin, S.S.; Gulevich, A.G.; Lagarias, J.C. Phycoviolobilin formation and spectral tuning in the DXCF cyanobacteriochrome subfamily. Biochemistry, 2012, 51(7), 14491463.

[52] Wiethaus, J.; Busch, A.W.U.; Dammeyer, T.; FrankenbergDinkel, N. Phycobiliproteins in Prochlorococcus marinus: Biosynthesis of pigments and their assembly into proteins. Eur. J. Cell Biol., 2010, 89(12), 1005-1010.

[53] Lee, R.E. Phycology; Cambridge University Press: Cambridge, 2008.

[54] Sepúlveda-Ugarte, J.; Brunet, J.E.; Matamala, A.R.; MartínezOyanedel, J.; Bunster, M. Spectroscopic parameters of phycoerythrobilin and phycourobilin on phycoerythrin from Gracilaria chilensis. J. Photochem. Photobiol. A Chem., 2011, 219(2-3), 211-216.

[55] Ishizuka, T.; Kamiya, A.; Suzuki, H.; Narikawa, R.; Noguchi, T.; Kohchi, T.; Inomata, K.; Ikeuchi, M. The cyanobacteriochrome, TePixJ, isomerizes its own chromophore by converting phycocyanobilin to phycoviolobilin. Biochemistry, 2011, 50(6), 953-961.

[56] Solymosi, K. Plastid structure, diversification and interconversions I. Algae. Curr. Chem. Biol., 2012, 6, 167-186.

[57] Klose, C.; Viczián, A.; Kircher, S.; Schäfer, E.; Nagy, F. Molecular mechanisms for mediating light-dependent nucleo/cytoplasmic partitioning of phytochrome photoreceptors. New Phytol., 2015, 206(3), 965-971.

[58] Colyer, C.L.; Kinkade, C.S.; Viskari, P.J.; Landers, J.P. Analysis of cyanobacterial pigments and proteins by electrophoretic and chromatographic methods. Anal. Bioanal. Chem., 2005, 382(3), 559-569.

[59] Blankenship, R.E. Molecular Mechanisms of Photosynthesis; Blackwell Science Ltd.: Oxford, 2002.

[60] Fernández-Rojas, B.; Hernández-Juárez, J.; Pedraza-Chaverri, J. Nutraceutical properties of phycocyanin. J. Funct. Foods, 2014, $11,375-392$.

[61] Sekar, S.; Chandramohan, M. Phycobiliproteins as a commodity: Trends in applied research, patents and commercialization. $J$. Appl. Phycol., 2008, 20(2), 113-136.

[62] de Lorimier, R.; Wilbanks, S.M.; Glazer, A.N. Genes of the Rphycocyanin II locus of marine Synechococcus spp., and comparison of protein-chromophore interactions in phycocyanins differing in bilin composition. Plant Mol. Biol., 1993, 21(2), 225237.

[63] Bermejo, R.; Tobaruela, D.J.; Talavera, E.M.; Orte, A.; AlvarezPez, J.M. Fluorescent behavior of B-phycoerythrin in microemulsions of aerosol OT/water/isooctane. J. Colloid Interface Sci., 2003, 263(2), 616-624.

[64] Kuddus, M.; Singh, P.; Thomas, G.; Al-Hazimi, A. Recent developments in production and biotechnological applications of C-phycocyanin. Biomed Res. Int., 2013, 2013, 742859.

[65] Zehetmayer, P.; Kupka, M.; Scheer, H.; Zumbusch, A. Energy transfer in monomeric phycoerythrocyanin. BBA - Bioenergetics, 2004, 1608(1), 35-44.

[66] Green, B.R.; Anderson, J.M.; Parson, W.W. In: Light-harvesting Antennas in Photosynthesis; Green, B.; Parson, W., Eds. Springer: Dordrecht, 2003; Advances in Photosynthesis and Respiration Vol. 13, pp. 1-28.

[67] Cerino, F.; Zingone, A. In: Unravelling the Algae, the Past, Present and Future of Algal Systematics; Brodie, J.; Lewis, J., Eds. CRC Press: Boca Raton, London, New York, 2007; The Systematics Association Special Volume Series 75, pp. 197-214.

[68] Adir, N. Elucidation of the molecular structures of components of the phycobilisome: reconstructing a giant. Photosynth. Res., 2005, 85(1), 15-32.

[69] Guan, X.; Qin, S.; Zhao, F.; Zhang, X.; Tang, X. Phycobilisomes linker family in cyanobacterial genomes: Divergence and evolution. Int. J. Biol. Sci., 2007, 3(7), 434-445.

[70] Ughy, B.; Ajlani, G. Phycobilisome rod mutants in Synechocystis sp. strain PCC6803. Microbiology, 2004, 150(12), 4147-4156.

[71] Sloth, J.K.; Wiebe, M.G.; Eriksen, N.T. Accumulation of phycocyanin in heterotrophic and mixotrophic cultures of the acidophilic red alga Galdieria sulphuraria. Enzyme Microb. Technol., 2006, 38(1-2), 168-175.

[72] Geiselmann, J.; Houmard, J.; Schoefs, B. In: Handbook of Photosynthesis; Pessarakli, M., Ed. Marcel Dekker: New York, Basel, Hong Kong, 2005; pp. 425-438.

[73] Ghosh, T.; Paliwal, C.; Maurya, R.; Mishra, S. In: Plant Biology and Biotechnology; Bahadur, B.; Rajam, M.V.; Sahijram, L.; Krishnamurthy, K.V., Eds. Springer: New Delhi, 2015; Plant Diversity, Organization, Function and Improvement Vol. 1, pp. 777-791.

[74] Zhou, Z.-P.; Liu, L.-N.; Chen, X.-L.; Wang, J.-X.; Chen, M.I.N.; Zhang, Y.-Z.; Zhou, B.-C. Factors that effect antioxidant activity of C-phycocyanins from Spirulina platensis. J. Food Biochem., 2005, 29(3), 313-322.

[75] Vali Aftari, R.; Rezaei, K.; Mortazavi, A.; Bandani, A.R. The optimized concentration and purity of Spirulina platensis Cphycocyanin: A comparative study on microwave-assisted and ultrasound-assisted extraction methods. J. Food Process. Preserv., 2015, 39(6), 3080-3091.

[76] Juin, C.; Chérouvrier, J.-R.; Thiéry, V.; Gagez, A.-L.; Bérard, J.B.; Joguet, N.; Kaas, R.; Cadoret, J.-P.; Picot, L. Microwaveassisted extraction of phycobiliproteins from Porphyridium purpureum. Appl. Biochem. Biotechnol., 2015, 175(1), 1-15.

[77] Bermejo Román, R.; Alvárez-Pez, J.M.; Acién Fernández, F.G.; Molina Grima, E. Recovery of pure B-phycoerythrin from the microalga Porphyridium cruentum. J. Biotechnol., 2002, 93(1), 73-85.

[78] Soni, B.; Kalavadia, B.; Trivedi, U.; Madamwar, D. Extraction, purification and characterization of phycocyanin from Oscillatoria quadripunctulata - Isolated from the rocky shores of Bet-Dwarka, Gujarat, India. Process Biochem., 2006, 41(9), 2017-2023.

[79] Yan, S.-G.; Zhu, L.-P.; Su, H.-N.; Zhang, X.-Y.; Chen, X.-L.; Zhou, B.-C.; Zhang, Y.-Z. Single-step chromatography for simultaneous purification of C-phycocyanin and allophycocyanin with high purity and recovery from Spirulina (Arthrospira) platensis. J. Appl. Phycol., 2011, 23(1), 1-6.

[80] Wrolstad, R.E.; Culver, C.A. Alternatives to those artificial FD\&C food colorants. Annu. Rev. Food Sci. Technol., 2012, 3(1), 59-77.

[81] Kumar, D.; Dhar, D.W.; Pabbi, S.; Kumar, N.; Walia, S. Extraction and purification of C-phycocyanin from Spirulina platensis (CCC540). Indian J. Plant Physiol., 2014, 19(2), 184188.

[82] Boussiba, S.; Richmond, A.E. Isolation and characterization of phycocyanins from the blue-green alga Spirulina platensis. Arch. Microbiol., 1979, 120(2), 155-159.

[83] Minkova, K.M.; Tchernov, A.A.; Tchorbadjieva, M.I.; Fournadjieva, S.T.; Antova, R.E.; Busheva, M.C. Purification of C-phycocyanin from Spirulina (Arthrospira) fusiformis. $J$. Biotechnol., 2003, 102(1), 55-59.

[84] Santiago-Santos, M.C.; Ponce-Noyola, T.; Olvera-Ramírez, R.; Ortega-López, J.; Cañizares-Villanueva, R.O. Extraction and purification of phycocyanin from Calothrix sp. Process Biochem., 2004, 39(12), 2047-2052.

[85] Liu, L.-N.; Chen, X.-L.; Zhang, X.-Y.; Zhang, Y.-Z.; Zhou, B.-C. One-step chromatography method for efficient separation and purification of R-phycoerythrin from Polysiphonia urceolata. $J$. Biotechnol., 2005, 116(1), 91-100.

[86] Rossano, R.; Ungaro, N.; D’Ambrosio, A.; Liuzzi, G.M.; Riccio, 
P. Extracting and purifying R-phycoerythrin from Mediterranean red algae Corallina elongata Ellis \& Solander. J. Biotechnol., 2003, 101(3), 289-293.

[87] Sun, L.; Wang, S.; Gong, X.; Zhao, M.; Fu, X.; Wang, L. Isolation, purification and characteristics of R-phycoerythrin from a marine macroalga Heterosiphonia japonica. Protein Expr. Purif., 2009, 64(2), 146-154.

[88] Niu, J.-F.; Wang, G.-C.; Tseng, C.-K. Method for large-scale isolation and purification of R-phycoerythrin from red alga Polysiphonia urceolata Grev. Protein Expr. Purif., 2006, 49(1), 23-31.

[89] Dufossé, L.; Galaup, P.; Yaron, A.; Arad, S.M.; Blanc, P.; Murthy, K.N.C.; Ravishankar, G.A. Microorganisms and microalgae as sources of pigments for food use: A scientific oddity or an industrial reality? Trends Food Sci. Technol., 2005, 16, 389-406.

[90] Bermejo, R.; Ruiz, E.; Acien, F.G. Recovery of B-phycoerythrin using expanded bed adsorption chromatography: Scale-up of the process. Enzyme Microb. Techn., 2007, 40(4), 927-933.

[91] Niu, J.-F.; Wang, G.-C.; Lin, X.; Zhou, B.-C. Large-scale recovery of $\mathrm{C}$-phycocyanin from Spirulina platensis using expanded bed adsorption chromatography. J. Chromatogr. B, 2007, 850(1-2), 267-276.

[92] Ramos, A.; Acién, G.F.; Fernández-Sevilla, J.M.; González, C.V; Bermejo, R. Large-scale isolation and purification of Cphycocyanin from the cyanobacteria Anabaena marina using expanded bed adsorption chromatography. J. Chem. Technol. Biotechnol., 2010, 85(6), 783-792.

[93] Moraes, C.C.; Sala, L.; Cerveira, G.P.; Kalil, S.J. C-phycocyanin extraction from Spirulina platensis wet biomass. Braz. J. Chem. Eng., 2011, 28(1), 45-49.

[94] Mishra, S.K.; Shrivastav, A.; Mishra, S. Effect of preservatives for food grade C-PC from Spirulina platensis. Process Biochem., 2008, 43(4), 339-345.

[95] Su, C.-H.; Liu, C.-S.; Yang, P.-C.; Syu, K.-S.; Chiuh, C.-C. Solidliquid extraction of phycocyanin from Spirulina platensis: Kinetic modeling of influential factors. Sep. Purif. Technol., 2014, 123, 64-68.

[96] Mortensen, A. Carotenoids and other pigments as natural colorants. Pure Appl. Chem., 2006, 78(8), 1477-1491.

[97] Sarada, R.; Pillai, M.G.; Ravishankar, G.A. Phycocyanin from Spirulina sp.: Influence of processing of biomass on phycocyanin yield, analysis of efficacy of extraction methods and stability studies on phycocyanin. Process Biochem., 1999, 34(8), 795-801.

[98] Zhao, J.; Brand, J.J. Specific bleaching of phycobiliproteins from cyanobacteria and red algae at high temperature in vivo. Arch. Microbiol., 1989, 152(5), 447-452.

[99] Romay, C.; González, R.; Ledón, N.; Remirez, D.; Rimbau, V. Cphycocyanin: a biliprotein with antioxidant, anti-inflammatory and neuroprotective effects. Curr. Protein Pept. Sci., 2003, 4(3), 207-216.

[100] Zhou, Z.P.; Liu, L.N.; Chen, X.L.; Zhang, X.Y.; Zhang, Y.Z.; Zhou, B.C. Effects of light, denaturants and $\mathrm{pH}$ on antioxidant activity of allophycocyanin in Spirulina platensis. Oceanol. Limnol. Sin., 2005, 36, 179-185.

[101] Jespersen, L.; Strømdahl, L.D.; Olsen, K.; Skibsted, L.H. Heat and light stability of three natural blue colorants for use in confectionery and beverages. Eur. Food Res. Technol., 2005, 220(3-4), 261-266.

[102] Iwamoto, K.; Aruga, Y.; Ohyabu, K. Change in color of dried sheet of laver, 'hoshi-nori', under heating and other conditions. $J$. Tokyo Univ. Fish., 1972, 58, 1-7.

[103] Amano, H.; Noda, H. Natural occurrence of denatured phycoerythrin during Porphyra cultivation. Hydrobiologia, 1993, 260-261(1), 535-539.

[104] Antelo, F.S.; Costa, J.A.V; Kalil, S.J. Thermal degradation kinetics of the phycocyanin from Spirulina platensis. Biochem. Eng. J., 2008, 41(1), 43-47.

[105] Berns, D.S.; MacColl, R. Phycocyanin in physical chemical studies. Chem. Rev., 1989, 89(4), 807-825.

[106] Le Jeune, H.; Joubert, Y.; Vilaume, C.; Fleurence, J. Propriétés et interêt biotechnologique d'un pigment algal: la R-phycoérythrine. Biofutur, 2003, 236, 34-38.

[107] Dainippon Ink and Chemicals Inc. Cosmetics containing water soluble phycocyanin. Japanese Patent 79-138755, 1981.

[108] Habib, M.A.B.; Parvin, M.; Huntington, T.C.; Hasan, M.R. A review on culture, production and use of spirulina as food for humans and feeds for domestic animals and fish. FAO Fish.
Aquac. Circ., No. 1034. FAO: Roma, 2008; pp. 1-33.

[109] Federal Code of Regulations, Title 21, part 73 on Listing of Color Additives Exempt From Certification, 78 FR 49117 https://federalregister.gov/a/2013-19550 (Accessed October 4, 2015).

[110] Bomgardner, M.M. The new naturals. Chem. Eng. News, 2014, 92, 10-13.

[111] Federal Code of Regulations, Title 21, part 73 on Listing of Color Additives Exempt From Certification, 79 FR 20095 https://federalregister.gov/a/2014-08099 (Accessed October 4, 2015).

[112] Federal Code of Regulations, Title 21, part 73 on Listing of Color Additives Exempt From Certification, 80 FR 50762 https://federalregister.gov/a/2015-20676 (Accessed October 4, 2015).

[113] Matulka, R.A.; Tardy, A.-L. Global focus: food colours vs colouring foods in the USA, EU, China, Russia and Brazil. Agro Food Ind. Hi Tech, 2014, 25, 7-9.

[114] Paniagua-Michel, J.; Dujardin, E.; Sironval, C. Le Tecuitlal, concentré de spirulines source de protéines comestibles chez les Azteques. Cah. l'Agriculture, 1993, 2, 283-287.

[115] Barsanti, L.; Gualtieri, P. Algae. Anatomy, Biochemistry and Biotechnology, $1^{\text {st }}$ ed.; CRC Press: Boca Raton, 2006.

[116] Benedetti, S.; Benvenuti, F.; Pagliarani, S.; Francogli, S.; Scoglio, S.; Canestrari, F. Antioxidant properties of a novel phycocyanin extract from the blue-green alga Aphanizomenon flos-aquae. Life Sci., 2004, 75(19), 2353-2362.

[117] Benedetti, S.; Benvenuti, F.; Scoglio, S.; Canestrari, F. Oxygen radical absorbance capacity of phycocyanin and phycocyanobilin from the food supplement Aphanizomenon flos-aquae. J. Med. Food, 2010, 13(1), 223-227.

[118] Qureshi, M.A.; Garlich, J.D.; Kidd, M.T. Dietary Spirulina platensis enhances humoral and cell-mediated immune functions in chickens. Immunopharmacol. Immunotoxicol., 1996, 18(3), 465-476.

[119] Jenson, G.S.; Ginsberg, D.I.; Drapeau, C. Blue-green algae as an immuno-enhancer and biomodulator. J. Am. Nutraceut. Ass., 2001, 3(4), 24-30.

[120] Sonani, R.R.; Rastogi, R.P.; Madamwar, D. Antioxidant potential of phycobiliproteins: Role in anti-aging research. Biochem. Anal. Biochem., 2015, 4(2), 172.

[121] Morcos, C.N.; Berns, M.; Henry, W.L. Phycocyanin: Laser activation, cytotoxic effects, and uptake in human atherosclerotic plaque. Lasers Surg. Med., 1988, 8(1), 10-17.

[122] Wang, C.-Y.; Wang, X.; Wang, Y.; Zhou, T.; Bai, Y.; Li, Y.-C.; Huang, B. Photosensitization of phycocyanin extracted from Microcystis in human hepatocellular carcinoma cells: Implication of mitochondria-dependent apoptosis. J. Photochem. Photobiol. B Biol., 2012, 117, 70-79.

[123] Soni, B.; Visavadiya, N.P.; Dalwadi, N.; Madamwar, D.; Winder, C.; Khalil, C. Purified C-phycoerythrin: safety studies in rats and protective role against permanganate-mediated fibroblast-DNA damage. J. Appl. Toxicol., 2010, 30(6), 542-550.

[124] Subhashini, J.; Mahipal, S.V.K.; Reddy, M.C.; Mallikarjuna Reddy, M.; Rachamallu, A.; Reddanna, P. Molecular mechanisms in C-phycocyanin induced apoptosis in human chronic myeloid leukemia cell line-K562. Biochem. Pharmacol., 2004, 68(3), 453462.

[125] Roy, K.R.; Arunasree, K.M.; Reddy, N.P.; Dheeraj, B.; Reddy, G.V.; Reddanna, P. Alteration of mitochondrial membrane potential by Spirulina platensis C-phycocyanin induces apoptosis in the doxorubicin resistant human hepatocellular-carcinoma cell line HepG2. Biotechnol. Appl. Biochem., 2007, 47(3), 159-167.

[126] Nishanth, R.P.; Ramakrishna, B.S.; Jyotsna, R.G.; Roy, K.R.; Reddy, G.V.; Reddy, P.K.; Reddanna, P. C-phycocyanin inhibits MDR1 through reactive oxygen species and cyclooxygenase-2 mediated pathways in human hepatocellular carcinoma cell line. Eur. J. Pharmacol., 2010, 649(1-3), 74-83.

[127] Wu, L.-C.; Lin, Y.-Y.; Yang, S.-Y.; Weng, Y.-T.; Tsai, Y.-T. Antimelanogenic effect of C-phycocyanin through modulation of tyrosinase expression by upregulation of ERK and downregulation of p38 MAPK signaling pathways. J. Biomed. Sci., 2011, 18(1), 74.

[128] Rimbau, V.; Camins, A.; Romay, C.; González, R.; Pallàs, M. Protective effects of C-phycocyanin against kainic acid-induced neuronal damage in rat hippocampus. Neurosci. Lett., 1999, 276(2), 75-78.

[129] Bermejo-Bescós, P.; Piñero-Estrada, E.; Villar del Fresno, Á. 
Neuroprotection by Spirulina platensis protean extract and phycocyanin against iron-induced toxicity in SH-SY5Y neuroblastoma cells. Toxicol. Vitr., 2008, 22(6), 1496-1502.

[130] Romay, C.; Ledón, N.; González, R. Further studies on antiinflammatory activity of phycocyanin in some animal models of inflammation. Inflamm. Res., 1998, 47(8), 334-338.

[131] Naidu, K.A.; Sarada, R.; Manoj, G.; Khan, M.Y.; Swamy, M.M.; Viswanatha, S.; Murthy, K.N.; Ravishankar, G.A.; Srinivas, L. Toxicity assessment of phycocyanin - A blue colorant from blue green alga Spirulina platensis. Food Biotechnol., 1999, 13(1), 5166.

[132] Ou, Y.; Lin, L.; Pan, Q.; Yang, X.; Cheng, X. Preventive effect of phycocyanin from Spirulina platensis on alloxan-injured mice. Environ. Toxicol. Pharmacol., 2012, 34(3), 721-726.

[133] Gupta, M.; Dwivedi, U.N.; Khandelwal, S. C-phycocyanin: An effective protective agent against thymic atrophy by tributyltin. Toxicol. Lett., 2011, 204(1), 2-11.

[134] Vadiraja, B.B.; Gaikwad, N.W.; Madyastha, K.M. Hepatoprotective effect of C-phycocyanin: protection for carbon tetrachloride and R-(+)-pulegone-mediated hepatotoxicty in rats. Biochem. Biophys. Res. Commun., 1998, 249(2), 428-431.

[135] Ge, B.; Qin, S.; Han, L.; Lin, F.; Ren, Y. Antioxidant properties of recombinant allophycocyanin expressed in Escherichia coli. $J$. Photochem. Photobiol. B Biol., 2006, 84(3), 175-180.

[136] Tang, Z.H.; Zhao, F.Q.; Qin, S.; Wu, S.J.; Gao, J.T.; Lin, L.P. The production of rAPC and the study of its inhibition effect on H22 tumor. High Technol. Lett., 2004, 3, 83-86.

[137] Sonani, R.R.; Singh, N.K.; Kumar, J.; Thakar, D.; Madamwar, D. Concurrent purification and antioxidant activity of phycobiliproteins from Lyngbya sp. A09DM: An antioxidant and anti-aging potential of phycoerythrin in Caenorhabditis elegans. Process Biochem., 2014, 49(10), 1757-1766.

[138] Sonani, R.R.; Singh, N.K.; Awasthi, A.; Prasad, B.; Kumar, J.; Madamwar, D. Phycoerythrin extends life span and health span of Caenorhabditis elegans. Age, 2014, 36(5), 9717.

[139] Soni, B.; Visavadiya, N.P.; Madamwar, D. Attenuation of diabetic complications by C-phycoerythrin in rats: antioxidant activity of C-phycoerythrin including copper-induced lipoprotein and serum oxidation. Br. J. Nutr., 2009, 102(1), 102-109.

[140] Piñero Estrada, J.; Bermejo Bescós, P.; Villar del Fresno, A.M. Antioxidant activity of different fractions of Spirulina platensis protein extract. Il Farmaco, 2001, 56(5-7), 497-500.

[141] Romay, C.; Armesto, J.; Remirez, D.; González, R.; Ledon, N.; García, I. Antioxidant and anti-inflammatory properties of Cphycocyanin from blue-green algae. Inflamm. Res., 1998, 47(1), 36-41.

[142] Patel, A.; Mishra, S.; Ghosh, P.K. Antioxidant potential of Cphycocyanin isolated from cyanobacterial species Lyngbya, Phormidium and Spirulina spp. Ind. J. Biochem. Biophys., 2006, 43, 25-31.

[143] Bermejo, P.; Piñero, E.; Villar, Á.M. Iron-chelating ability and antioxidant properties of phycocyanin isolated from a protean extract of Spirulina platensis. Food Chem., 2008, 110(2), 436-445.

[144] Fernández-Rojas, B.; Medina-Campos, O.N.; Hernandez-Pando, R.; Negrette-Guzman, M.; Huerta-Yepez, S.; Pedraza-Chaverri, J. C-phycocyanin prevents cisplatin-induced nephrotoxicity through inhibition of oxidative stress. Food Funct., 2014, 5(3), 480-490.

[145] Romay, C.; González, R. Phycocyanin is an antioxidant protector of human erythrocytes against lysis by peroxyl radicals. J. Pharm. Pharmacol., 2000, 52(4), 367-368.

[146] Lissi, E.A.; Pizarro, M.; Aspee, A.; Romay, C. Kinetics of phycocyanine bilin groups destruction by peroxyl radicals. Free Radic. Biol. Med., 2000, 28(7), 1051-1055.

[147] Pleonsil, P.; Soogarun, S.; Suwanwong, Y. Anti-oxidant activity of holo- and apo-c-phycocyanin and their protective effects on human erythrocytes. Int. J. Biol. Macromol., 2013, 60, 393-398.

[148] Tapia, G.; Galetovic, A.; Lemp, E.; Pino, E.; Lissi, E. Singlet oxygen-mediated photobleaching of the prosthetic group in hemoglobins and C-phycocyanin. Photochem. Photobiol., 1999, 70(4), 499-504.

[149] Romay, C.; Gonzalez, R.; Pizarro, M.; Lissi, E. Kinetics of Cphycocyanin reaction with hypochlorite. J. Protein Chem., 2000, 19(2), 151-155.

[150] Bhat, V.B.; Madyastha, K.M. Scavenging of peroxynitrite by phycocyanin and phycocyanobilin from Spirulina platensis: Protection against oxidative damage to DNA. Biochem. Biophys. Res. Commun., 2001, 285(2), 262-266.

[151] Thangam, R.; Suresh, V.; Asenath Princy, W.; Rajkumar, M.;
Senthilkumar, N.; Gunasekaran, P.; Rengasamy, R.; Anbazhagan, C.; Kaveri, K.; Kannan, S. C-phycocyanin from Oscillatoria tenuis exhibited an antioxidant and in vitro antiproliferative activity through induction of apoptosis and G0/G1 cell cycle arrest. Food Chem., 2013, 140(1-2), 262-272.

[152] Huang, Z.; Guo, B.J.; Wong, R.N.S.; Jiang, Y. Characterization and antioxidant activity of selenium-containing phycocyanin isolated from Spirulina platensis. Food Chem., 2007, 100(3), 1137-1143.

[153] Chen, T.; Wong, Y.S. In vitro antioxidant and antiproliferative activities of selenium-containing phycocyanin from seleniumenriched Spirulina platensis. J. Agric. Food Chem., 2008, 56(12), 4352-4358.

[154] Bhat, V.B.; Madyastha, K.M. C-phycocyanin: A potent peroxyl radical scavenger in vivo and in vitro. Biochem. Biophys. Res. Commun., 2000, 275(1), 20-25.

[155] Sun, Y.; Zhang, J.; Yan, Y.; Chi, M.; Chen, W.; Sun, P.; Qin, S. The protective effect of C-phycocyanin on paraquat-induced acute lung injury in rats. Environ. Toxicol. Pharmacol., 2011, 32(2), 168-174.

[156] Hirata, T.; Tanaka, M.; Ooike, M.; Tsunomura, T.; Sakaguchi, M. Antioxidant activities of phycocyanobilin prepared from Spirulina platensis. J. Appl. Phycol., 2000, 12(3-5), 435-439.

[157] He, J.-A.; Hu, Y.-Z.; Jiang, L.-J. Photodynamic action of phycobiliproteins: in situ generation of reactive oxygen species. BBA - Bioenergetics, 1997, 1320(2), 165-174.

[158] Zhang, H.; Chen, T.; Jiang, J.; Wong, Y.-S.; Yang, F.; Zheng, W. Selenium-containing allophycocyanin purified from seleniumenriched Spirulina platensis attenuates AAPH-induced oxidative stress in human erythrocytes through inhibition of ROS generation. J. Agric. Food Chem., 2011, 59(16), 8683-8690.

[159] Pádula, M.; Boiteux, S. Photodynamic DNA damage induced by phycocyanin and its repair in Saccharomyces cerevisiae. Braz. J. Med. Biol. Res., 1999, 32(9), 1063-1071.

[160] Madhyastha, H.K.; Sivashankari, S.; Vatsala, T.M. C-phycocyanin from Spirulina fussiformis exposed to blue light demonstrates higher efficacy of in vitro antioxidant activity. Biochem. Eng. J., 2009, 43(2), 221-224.

[161] Madhyastha, H.K.; Vatsala, T.M. Cysteine-rich cyanopeptide beta2 from Spirulina fusiformis exhibits plasmid DNA pBR322 scission prevention and cellular antioxidant activity. Indian $J$. Exp. Biol., 2010, 48(5), 486-493.

[162] Padula, M.; Boiteux, S.; Felzenszwalb, I.; Menezes, S. Photodynamic-action of phycocyanin damage and repair. $J$. Photochem. Photobiol. B Biol., 1996, 32(1-2), 19-26.

[163] Hu, L.; Huang, B.; Zuo, M.-M.; Guo, R.-Y.; Wei, H. Preparation of the phycoerythrin subunit liposome in a photodynamic experiment on liver cancer cells. Acta Pharmacol. Sin., 2008, 29(12), 1539-1546.

[164] Pan, Q.; Chen, M.; Li, J.; Wu, Y.; Zhen, C.; Liang, B. Antitumor function and mechanism of phycoerythrin from Porphyra haitanensis. Biol. Res., 2013, 46(1), 87-95.

[165] Huang, B.; Wang, G.-C.; Zeng, C.-K.; Li, Z. The experimental research of R-phycoerythrin subunits on cancer treatment: A new photosensitizer in PDT. Cancer Biother. Radiopharm., 2002, 17(1), 35-42.

[166] Wang, Y.; Cai, C.; Li, B.; Liu, C.; He, P. Photodynamic effect of two kinds of phycobiliproteins on human liver cancer cell line SMMC-7721 in vitro. Chin. J. Biotechnol., 2009, 25(9), 14171423.

[167] Li, B.; Chu, X.; Gao, M.; Li, W. Apoptotic mechanism of MCF-7 breast cells in vivo and in vitro induced by photodynamic therapy with C-phycocyanin. Acta Biochim. Biophys. Sin., 2010, 42(1), 80-89.

[168] Wang, H.; Liu, Y.; Gao, X.; Carter, C.L.; Liu, Z.-R. The recombinant $\beta$ subunit of $C$-phycocyanin inhibits cell proliferation and induces apoptosis. Cancer Lett., 2007, 247(1), 150-158.

[169] Pardhasaradhi, B.V.V.; Ali, M.A.; Kumari, L.A.; Reddanna, P.; Khar, A. Phycocyanin-mediated apoptosis in AK-5 tumor cells involves down-regulation of Bcl-2 and generation of ROS. Mol. Cancer Ther., 2003, 2(11), 1165-1170.

[170] Li, B.; Gao, M.-H.; Zhang, X.-C.; Chu, X.-M. Molecular immune mechanism of C-phycocyanin from Spirulina platensis induces apoptosis in HeLa cells in vitro. Biotechnol. Appl. Biochem., 2006, 43(3), 155-164.

[171] Tantirapan, P.; Suwanwong, Y. Anti-proliferative effects of Cphycocyanin on a human leukemic cell line and induction of apoptosis via the PI3K / AKT pathway. J. Chem. Pharm. Res., 
2014, 6(5), 1295-1301.

[172] Liu, Y.; Xu, L.; Cheng, N.; Lin, L.; Zhang, C. Inhibitory effect of phycocyanin from Spirulina platensis on the growth of human leukemia K562 cells. J. Appl. Phycol., 2000, 12(2), 125-130.

[173] Gantar, M.; Simović, D.; Djilas, S.; Gonzalez, W.W.; Miksovska, J. Isolation, characterization and antioxidative activity of Cphycocyanin from Limnothrix sp. strain 37-2-1. J. Biotechnol., 2012, 159(1-2), 21-26.

[174] Gantar, M.; Dhandayuthapani, S.; Rathinavelu, A. Phycocyanin induces apoptosis and enhances the effect of topotecan on prostate cell line LNCaP. J. Med. Food, 2012, 15(12), 1091-1095.

[175] Yang, F.; Li, B.; Chu, X.-M.; Lv, C.-Y.; Xu, Y.-J.; Yang, P. Molecular mechanism of inhibitory effects of C-phycocyanin combined with all-trans-retinoic acid on the growth of HeLa cells in vitro. Tumor Biol., 2014, 35(6), 5619-5628.

[176] Li, B.; Zhang, X.; Gao, M.; Chu, X. Effects of CD59 on antitumoral activities of phycocyanin from Spirulina platensis. Biomed. Pharmacother., 2005, 59(10), 551-560.

[177] Konícková, R.; Vanková, K.; Vaníková, J.; Vánová, K.; Muchová, L.; Subhanová, I.; Zadinová, M.; Zelenka, J.; Dvorák, A.; Kolár, M.; Strnad, H.; Rimpelová, S.; Ruml, T.; Wong, J.R.; Vítek, L. Anti-cancer effects of blue-green alga Spirulina platensis, a natural source of bilirubin-like tetrapyrrolic compounds. Ann. Hepatol., 2014, 13(2), 273-283.

[178] Gupta, N.K.; Gupta, K.P. Effects of C-phycocyanin on the representative genes of tumor development in mouse skin exposed to 12-O-tetradecanoyl-phorbol-13-acetate. Environ. Toxicol. Pharmacol., 2012, 34(3), 941-948.

[179] Ou, Y.; Yuan, Z.; Li, K.; Yang, X. Phycocyanin may suppress Dgalactose-induced human lens epithelial cell apoptosis through mitochondrial and unfolded protein response pathways. Toxicol. Lett., 2012, 215(1), 25-30.

[180] Cian, R.E.; López-Posadas, R.; Drago, S.R.; de Medina, F.S.; Martínez-Augustin, O. Immunomodulatory properties of the protein fraction from Phorphyra columbina. J. Agric. Food Chem., 2012, 60(33), 8146-8154.

[181] Romay, C.; Ledón, N.; González, R. Phycocyanin extract reduces leukotriene B4 levels in arachidonic acid-induced mouse-ear inflammation test. J. Pharm. Pharmacol., 1999, 51(5), 641-642.

[182] Romay, C.; Ledón, N.; González, R. Effects of phycocyanin extract on prostaglandin E2 levels in mouse ear inflammation test. Arzneimittelforschung, 2000, 50(12), 1106-1109.

[183] Manconia, M.; Pendás, J.; Ledón, N.; Moreira, T.; Sinico, C.; Saso, L.; Fadda, A.M. Phycocyanin liposomes for topical antiinflammatory activity: in-vitro in-vivo studies. J. Pharm. Pharmacol., 2009, 61(4), 423-430.

[184] Remirez, D.; González, A.; Merino, N.; González, R.; Ancheta, O.; Romay, C.; Rodríguez, S. Effect of phycocyanin in zymosaninduced arthritis in mice - phycocyanin as an antiarthritic compound. Drug Dev. Res., 1999, 48(2), 70-75.

[185] González, R.; Rodríguez, S.; Romay, C.; Ancheta, O.; González, A.; Armesto, J.; Remirez, D.; Merino, N. Anti-inflammatory activity of phycocyanin extract in acetic acid-induced colitis in rats. Pharmacol. Res., 1999, 39(1), 55-59.

[186] Shih, C.-M.; Cheng, S.-N.; Wong, C.-S.; Kuo, Y.-L.; Chou, T.-C. Antiinflammatory and antihyperalgesic activity of C-phycocyanin. Anesth. Analg., 2009, 108(4), 1303-1310.

[187] Remirez, D.; Ledón, N.; González, R. Role of histamine in the inhibitory effects of phycocyanin in experimental models of allergic inflammatory response. Mediators Inflamm., 2002, 11(2), 81-85.

[188] Cherng, S.-C.; Cheng, S.-N.; Tarn, A.; Chou, T.-C. Antiinflammatory activity of C-phycocyanin in lipopolysaccharidestimulated RAW 264.7 macrophages. Life Sci., 2007, 81(19-20), 1431-1435

[189] Chen, J.-C.; Liu, K.S.; Yang, T.-J.; Hwang, J.-H.; Chan, Y.-C.; Lee, I.-T. Spirulina and C-phycocyanin reduce cytotoxicity and inflammation-related genes expression of microglial cells. Nutr. Neurosci., 2012, 15(6), 252-256.

[190] Reddy, C.M.; Bhat, V.B.; Kiranmai, G.; Reddy, M.N.; Reddanna, P.; Madyastha, K.M. Selective inhibition of cyclooxygenase-2 by C-phycocyanin, a biliprotein from Spirulina platensis. Biochem. Biophys. Res. Commun., 2000, 277(3), 599-603.

[191] Reddy, M.C.; Subhashini, J.; Mahipal, S.V.; ; Bhat, V.B.; Srinivas Reddy, P.; Kiranmai, G.; Madyastha, K.M.; Reddanna, P. C-phycocyanin, a selective cyclooxygenase-2 inhibitor, induces apoptosis in lipopolysaccharide-stimulated RAW 264.7 macrophages. Biochem. Biophys. Res. Commun., 2003, 304(2),
385-392.

[192] Chen, H.-W.; Yang, T.-S.; Chen, M.-J.; Chang, Y.-C.; Wang, E.I.C.; Ho, C.-L.; Lai, Y.-J.; Yu, C.-C.; Chou, J.-C.; Chao, L.K.-P.; Liao, P.-C. Purification and immunomodulating activity of Cphycocyanin from Spirulina platensis cultured using power plant flue gas. Process Biochem., 2014, 49(8), 1337-1344.

[193] Leung, P.-O.; Lee, H.-H.; Kung, Y.-C.; Tsai, M.-F.; Chou, T.-C. Therapeutic effect of C-phycocyanin extracted from blue green algae in a rat model of acute lung injury induced by lipopolysaccharide. Evidence-Based Complement. Altern. Med. 2013, 2013, 916590.

[194] Hwang, J.-H.; Chen, J.-C.; Chan, Y.-C. Effects of C-phycocyanin and Spirulina on salicylate-induced tinnitus, expression of NMDA receptor and inflammatory genes. PLoS ONE, 2013, 8(3), e58215.

[195] Nemoto-Kawamura, C.; Hirahashi, T.; Nagai, T.; Yamada, H.; Katoh, T.; Hayashi, O. Phycocyanin enhances secretary IgA antibody response and suppresses allergic IgE antibody response in mice immunized with antigen-entrapped biodegradable microparticles. J. Nutr. Sci. Vitaminol., 2004, 50, 129-136.

[196] Pentón-Rol, G.; Martínez-Sánchez, G.; Cervantes-Llanos, M.; Lagumersindez-Denis, N.; Acosta-Medina, E.F.; Falcón-Cama, V.; Alonso-Ramírez, R.; Valenzuela-Silva, C.; RodríguezJiménez, E.; Llópiz-Arzuaga, A.; Marín-Prida, J.; López-Saura, P.A., Guillén-Nieto, G.E.; Pentón-Arias, E. C-phycocyanin ameliorates experimental autoimmune encephalomyelitis and induces regulatory T cells. Int. Immunopharmacol., 2011, 11(1), 29-38.

[197] McCarty, M.F. Clinical potential of phycocyanobilin for induction of $\mathrm{T}$ regulatory cells in the management of inflammatory disorders. Med. Hypotheses, 2011, 77(6), 1031-1033.

[198] Ou, Y.; Zheng, S.; Lin, L.; Jiang, Q.; Yang, X. Protective effect of C-phycocyanin against carbon tetrachloride-induced hepatocyte damage in vitro and in vivo. Chem. Biol. Interact., 2010, 185(2), 94-100.

[199] Nagaraj, S.; Arulmurugan, P.; Karuppasamy, K.; Jayappriyan, K.R.; Sundararaj, R.; Vijayanand, N.; Rengasamy, R Hepatoprotective and antioxidative effects of C-phycocyanin in $\mathrm{CCl}_{4}$ induced hepatic damage rats. Acad. J. Cancer Res., 2011, 4(2), 29-34.

[200] González, R.; González, A.; Remirez, D.; Romay, C.; Rodriguez, S.; Ancheta, O.; Merino, N. Protective effects of phycocyanin on galactosamine-induced hepatitis in rats. Biotecnol. Apl., 2003, 20, 107-110.

[201] Soni, B.; Visavadiya, N.P.; Madamwar, D. Ameliorative action of cyanobacterial phycoerythrin on $\mathrm{CCl}_{4}$-induced toxicity in rats. Toxicology, 2008, 248(1), 59-65.

[202] Farooq, S.M.; Ebrahim, A.S.; Subramhanya, K.H.; Sakthivel, R.; Rajesh, N.G.; Varalakshmi, P. Oxalate mediated nephronal impairment and its inhibition by C-phycocyanin: A study on urolithic rats. Mol. Cell. Biochem., 2006, 284(1-2), 95-101.

[203] Rodríguez-Sánchez, R.; Ortiz-Butrón, R.; Blas-Valdivia, V.; Hernández-García, A.; Cano-Europa, E. Phycobiliproteins or Cphycocyanin of Arthrospira (Spirulina) maxima protect against $\mathrm{HgCl}_{2}$-caused oxidative stress and renal damage. Food Chem. 2012, 135(4), 2359-2365.

[204] Cano-Europa, E.; Ortiz-Butrón, R.; Gallardo-Casas, C.A.; BlasValdivia, V.; Pineda-Reynoso, M.; Olvera-Ramírez, R.; FrancoColin, M. Phycobiliproteins from Pseudanabaena tenuis rich in Cphycoerythrin protect against $\mathrm{HgCl}_{2}$-caused oxidative stress and cellular damage in the kidney. J. Appl. Phycol., 2010, 22(4), 495501.

[205] Remirez, D.; Fernández, V.; Tapia, G.; González, R.; Videla, L.A. Influence of $\mathrm{C}$-phycocyanin on hepatocellular parameters related to liver oxidative stress and Kupffer cell functioning. Inflamm. Res., 2002, 51(7), 351-356.

[206] Hussein, M.M.; Ali, H.A.; Ahmed, M.M. Ameliorative effects of phycocyanin against gibberellic acid induced hepatotoxicity. Pestic. Biochem. Physiol., 2015, 119, 28-32.

[207] Minic, S.L.; Milcic, M.; Stanic-Vucinic, D.; Radibratovic, M.; Sotiroudis, T.G.; Nikolic, M.R.; Velickovic, T.C. Phycocyanobilin, a bioactive tetrapyrrolic compound of bluegreen alga Spirulina, binds with high affinity and competes with bilirubin for binding on human serum albumin. RSC Adv., 2015 5(76), 61787-61798.

[208] Terry, M.J.; Maines, M.D.; Lagarias, J.C.; Mainesi, M.D.; Lagariassil, J.C. Inactivation of phytochrome- and phycobiliprotein-chromophore precursors by rat liver biliverdin reductase. J. Biol. Chem., 1993, 268(35), 26099-26106. 
[209] Riss, J.; Décordé, K.; Sutra, T.; Delage, M.; Baccou, J.C.; Jouy, N.; Brune, J.P.; Oréal, H.; Cristol, J.P.; Rouanet, J.M. Phycobiliprotein C-phycocyanin from Spirulina platensis is powerfully responsible for reducing oxidative stress and NADPH oxidase expression induced by an atherogenic diet in hamsters. $J$. Agric. Food Chem., 2007, 55(19), 7962-7967.

[210] McCarty, M.F.; Barroso-Aranda, J.; Contreras, F. Genistein and phycocyanobilin may prevent hepatic fibrosis by suppressing proliferation and activation of hepatic stellate cells. Med. Hypotheses, 2009, 72(3), 330-332.

[211] Sathyasaikumar, K.V.; Swapna, I.; Reddy, P.V.B.; Murthy, C.R.K.; Roy, K.R.; Dutta Gupta, A.; Senthilkumaran, B.; Reddanna, P. Co-administration of C-phycocyanin ameliorates thioacetamide-induced hepatic encephalopathy in Wistar rats. $J$. Neurol. Sci., 2007, 252(1), 67-75.

[212] Farooq, S.M.; Asokan, D.; Sakthivel, R.; Kalaiselvi, P.; Varalakshmi, P. Salubrious effect of C-phycocyanin against oxalate-mediated renal cell injury. Clin. Chim. Acta, 2004, 348(12), 199-205.

[213] Farooq, S.M.; Boppana, N.B.; Asokan, D.; Sekaran, S.D.; Shankar, E.M.; Li, C.; Gopal, K.; Bakar, S.A.; Karthik, H.S.; Ebrahim, A.S. C-phycocyanin confers protection against oxalatemediated oxidative stress and mitochondrial dysfunctions in MDCK cells. PLoS ONE, 2014, 9(4), e93056.

[214] Rimbau, V.; Camins, A.; Pubill, D.; Sureda, F.X.; Romay, C.; González, R.; Jiménez, A.; Escubedo, E.; Camarasa, J.; Pallás, M.A. C-phycocyanin protects cerebellar granule cells from low potassium/serum deprivation-induced apoptosis. Naunyn Schmiedebergs Arch. Pharmacol., 2001, 364(2), 96-104.

[215] Pentón-Rol, G.; Marín-Prida, J.; Pardo-Andreu, G.; MartínezSánchez, G.; Acosta-Medina, E.F.; Valdivia-Acosta, A.; Lagumersindez-Denis, N.; Rodríguez-Jiménez, E.; LlópizArzuaga, A.; López-Saura, P.A.; Guillén-Nieto, G.; Pentón-Arias, E. C-phycocyanin is neuroprotective against global cerebral ischemia/reperfusion injury in gerbils. Brain Res. Bull., 2011, 86(1-2), 42-52.

[216] Marín-Prida, J.; Pentón-Rol, G.; Rodrigues, F.P.; Alberici, L.C.; Stringhetta, K.; Leopoldino, A.M.; Naal, Z.; Polizello, A.C.M.; Llópiz-Arzuaga, A.; Rosa, M.N.; Liberato, J.L.; Santos, W.F.; Uyemura, S.A.; Pentón-Arias, E.; Curti, C.; Pardo-Andreu, G.L. C-phycocyanin protects SH-SY5Y cells from oxidative injury, rat retina from transient ischemia and rat brain mitochondria from $\mathrm{Ca}^{2+} /$ phosphate-induced impairment. Brain Res. Bull., 2012, 89(56), 159-167.

[217] McCarty, M.F. Clinical potential of Spirulina as a source of phycocyanobilin. J. Med. Food, 2007, 10(4), 566-570.

[218] McCarty, M.F.; Barroso-Aranda, J.; Contreras, F. Oral phycocyanobilin may diminish the pathogenicity of activated brain microglia in neurodegenerative disorders. Med. Hypotheses, 2010, 74(3), 601-605.

[219] Hsiao, G.; Chou, P.-H.; Shen, M.-Y.; Chou, D.-S.; Lin, C.-H.; Sheu, J.-R. C-phycocyanin, a very potent and novel platelet aggregation inhibitor from Spirulina platensis. J. Agric. Food Chem., 2005, 53(20), 7734-7740.

[220] Chiu, H.-F.; Yang, S.-P.; Kuo, Y.-L.; Lai, Y.-S.; Chou, T.-C. Mechanisms involved in the antiplatelet effect of C-phycocyanin. Br. J. Nutr., 2006, 95(02), 435-440.

[221] Madhyastha, H.K.; Radha, K.S.; Sugiki, M.; Omura, S.; Maruyama, M. Purification of c-phycocyanin from Spirulina fusiformis and its effect on the induction of urokinase-type plasminogen activator from calf pulmonary endothelial cells. Phytomedicine, 2006, 13(8), 564-569.

[222] Madhyastha, H.K.; Radha, K.S.; Nakajima, Y.; Omura, S.; Maruyama, M. uPA dependent and independent mechanisms of wound healing by C-phycocyanin. J. Cell. Mol. Med., 2008, 12(6B), 2691-2703.

[223] Zheng, J.; Inoguchi, T.; Sasaki, S.; Maeda, Y.; McCarty, M.F.; Fujii, M.; Ikeda, N.; Kobayashi, K.; Sonoda, N.; Takayanagi, R. Phycocyanin and phycocyanobilin from Spirulina platensis protect against diabetic nephropathy by inhibiting oxidative stress. Am. J. Physiol. Regul. Integr. Comp. Physiol., 2013, 304(2), R110-R120.

[224] Li, X.-L.; Xu, G.; Chen, T.; Wong, Y.-S.; Zhao, H.-L.; Fan, R.-R.; Gu, X.-M.; Tong, P.C.Y.; Chan, J.C.N. Phycocyanin protects INS$1 \mathrm{E}$ pancreatic beta cells against human islet amyloid polypeptideinduced apoptosis through attenuating oxidative stress and modulating JNK and p38 mitogen-activated protein kinase pathways. Int. J. Biochem. Cell Biol., 2009, 41(7), 1526-1535.

Strasky, Z.; Zemankova, L.; Nemeckova, I.; Rathouska, J.; Wong,

\section{[226]}

R.J.; Muchova, L.; Subhanova, I.; Vanikova, J.; Vanova, K.; Vitek, L.; Nachtigal, P. Spirulina platensis and phycocyanobilin activate atheroprotective heme oxygenase-1: a possible implication for atherogenesis. Food Funct., 2013, 4, 1586-1594.

Nagaoka, S.; Shimizu, K.; Kaneko, H.; Shibayama, F.; Morikawa, K.; Kanamaru, Y.; Otsuka, A.; Hirahashi, T.; Kato, T. A novel protein C-phycocyanin plays a crucial role in the hypocholesterolemic action of Spirulina platensis concentrate in rats. J. Nutr., 2005, 135(10), 2425-2430.

Kothadia, A.D.; Shenoy, A.M.; Shabaraya, A.R.; Rajan, M.S.; Viradia, U.M.; Patel, N.H. Evaluation of cataract preventive action of phycocyanin. Int. J. Pharm. Sci. Drug Res., 2011, 3(1), 42-44.

Kumari, R.P.; Anbarasu, K. Protective role of C-phycocyanin against secondary changes during sodium selenite mediated cataractogenesis. Nat. Products Bioprospect., 2014, 4(2), 81-89.

Ivanova, K.G.; Stankova, K.G.; Nikolov, V.N.; Georgieva, R.T.; Minkova, K.M.; Gigova, L.G.; Rupova, I.T.; Boteva, R.N. The biliprotein C-phycocyanin modulates the early radiation response: A pilot study. Mutat. Res. Toxicol. Environ. Mutagen., 2010, 695(1-2), 40-45.

Khan, M.; Varadharaj, S.; Shobha, J.C.; Naidu, M.U.; Parinandi, N.L.; Kutala, V.K.; Kuppusamy, P. C-phycocyanin ameliorates doxorubicin-induced oxidative stress and apoptosis in adult rat cardiomyocytes. J. Cardiovasc. Pharmacol., 2006, 47(1), 9-20.

Khan, M.; Varadharaj, S.; Ganesan, L.P.; Shobha, J.C.; Naidu, M.U.; Parinandi, N.L.; Tridandapani, S.; Kutala, V.K.; Kuppusamy, P. C-phycocyanin protects against ischemiareperfusion injury of heart through involvement of p38 MAPK and ERK signaling. Am. J. Physiol. Heart Circ. Physiol., 2006, 290(5), H2136-H2145.

Roy, K.R.; Arunasree, K.M.; Dhoot, A.; Aparna, R.; Reddy, G.V.; Vali, S.; Reddanna, P. C-phycocyanin inhibits 2acetylaminofluorene-induced expression of MDR1 in mouse macrophage cells: ROS mediated pathway determined via combination of experimental and in silico analysis. Arch. Biochem. Biophys., 2007, 459(2), 169-177.

Roy, K.R.; Nishanth, R.P.; Sreekanth, D.; Reddy, G.V.; Reddanna, P. C-phycocyanin ameliorates 2-acetylaminofluorene induced oxidative stress and MDR1 expression in the liver of albino mice. Hepatol. Res., 2008, 38(5), 511-520.

Shih, S.-R.; Tsai, K.-N.; Li, Y.-S.; Chueh, C.-C.; Chan, E.-C. Inhibition of enterovirus 71-induced apoptosis by allophycocyanin isolated from a blue-green alga Spirulina platensis. J. Med. Virol., 2003, 70(1), 119-125.

Chattopadhyay, P.K.; Gaylord, B.; Palmer, A.; Jiang, N.; Raven, M.A.; Lewis, G.; Reuter, M.A.; Nur-ur Rahman, A.K.; Price, D.A.; Betts, M.R.; Roederer, M. Brilliant violet fluorophores: A new class of ultrabright fluorescent compounds for immunofluorescence experiments. Cytom. Part A, 2012, 81A(6), 456-466.

Oi, V.T.; Glazer, A.N.; Stryer, L. Fluorescent phycobiliprotein conjugates for analyses of cells and molecules. J. Cell Biol., 1982, 93(3), 981-986.

Telford, W.G.; Moss, M.W.; Morseman, J.; Allnutt, F.C. Cryptomonad algal phycobiliproteins as fluorochromes for extracellular and intracellular antigen detection by flow cytometry. Cytometry, 2001, 44(1), 16-23.

Roederer, M.; Kantor, A.B.; Parks, D.R.; Herzenberg, L.A. Cy7PE and Cy7APC: Bright new probes for immunofluorescence. Cytometry, 1996, 24(3), 191-197.

Bailey, M.P.; Rocks, B.F.; Riley, C. On the use of fluorescent labels in immunoassay. J. Pharm. Biomed. Anal., 1987, 5(7), 649658.

Glazer, A.N.; Stryer, L. Phycofluor probes. Trends Biochem. Sci., 1984, 5(1), 423-427.

Glazer, A.N. Phycobiliproteins - a family of valuable, widely used fluorophores. J. Appl. Phycol., 1994, 6(2), 105-112.

Siiman, O.; Wilkinson, J.; Burshteyn, A.; Roth, P.; Ledis, S. Fluorescent neoglycoproteins: Antibody-aminodextranphycobiliprotein conjugates. Bioconjug. Chem., 1999, 10(6), 1090-1106.

Sun, L.; Wang, S.; Chen, L.; Gong, X. Promising fluorescent probes from phycobiliproteins. IEEE J. Sel. Top. Quantum Electron., 2003, 9(2), 177-188.

EFSA Panel on Food Additives and Nutrient Sources added to Food. Scientific Opinion on re-evaluation of chlorophyllins (E 140(ii)) as food additives. Off. J. Eur. Union, 2015, 13(5), 1-42. 
[245] GPO Access. Electronic Code of Federal Regulations: Listing of Color Additives Exempt from Certification Available at http://www.ecfr.gov/cgi-

bin/retrieveECFR?gp=\&SID=3463c48f55ae08efd099682901bb95 00\&r=PART\&n=pt21.1.73. (Accessed September 26, 2015).

[246] Batista, A.P.; Raymundo, A.; Sousa, I.; Empis, J. Rheological characterization of coloured oil-in-water food emulsions with lutein and phycocyanin added to the oil and aqueous phases. Food Hydrocoll., 2006, 20(1), 44-52.

[247] Mishra, S.K.; Shrivastav, A.; Pancha, I.; Jain, D.; Mishra, S. Effect of preservatives for food grade C-phycoerythrin, isolated from marine cyanobacteria Pseudanabaena sp. Int. J. Biol. Macromol., 2010, 47(5), 597-602.

[248] Graverholt, O.S.; Eriksen, N.T. Heterotrophic high-cell-density fed-batch and continuous-flow cultures of Galdieria sulphuraria and production of phycocyanin. Appl. Microbiol. Biotechnol., 2007, 77(1), 69-75.

[249] Zhao, F.Q.; Tang, Z.H.; Lin, F.; Bao, L.; Qin, S.; Dou, C.G. High cell density fermentation of a recombinant E. coli strain P1 producing an anti-S180 tumor recombinant protein (rAPC). High Technol. Lett., 2003, 2, 29-33.

[250] Ge, B.; Tang, Z.; Zhao, F.; Ren, Y.; Yang, Y.; Qin, S. Scale-up of fermentation and purification of recombinant allophycocyanin over-expressed in Escherichia coli. Process Biochem., 2005, 40(10), 3190-3195.

[251] Hou, Y.-H.; Qin, S.; Li, Y.-X.; Li, F.-C.; Xia, H.-Z.; Zhao, F.-Q. Heterologous expression and purification of recombinant allophycocyanin in marine Streptomyces sp. isolate M097. World J. Microbiol. Biotechnol., 2006, 22(5), 525-529.
[252] Soni, B.; Trivedi, U.; Madamwar, D. A novel method of single step hydrophobic interaction chromatography for the purification of phycocyanin from Phormidium fragile and its characterization for antioxidant property. Bioresour. Technol., 2008, 99(1), 188194.

[257] Yan, M.; Liu, B.; Jiao, X.; Qin, S. Preparation of phycocyanin microcapsules and its properties. Food Bioprod. Process., 2014, 92(1), 89-97.

[258] Sapsford, K.E.; Algar, W.R.; Berti, L.; Gemmill, K.B.; Casey, B.J.; Oh, E.; Stewart, M.H.; Medintz, I.L. Functionalizing nanoparticles with biological molecules: Developing chemistries that facilitate nanotechnology. Chem. Rev., 2013, 113(3), 19042074. 